\title{
Análisis de «marcas externas epigráficas» en terra sigillata hispánica en la antigua provincia de la Lusitania
}

\author{
Analysis of «external epigraphic marks» in hispanic terra sigillata in \\ the province of Lusitania
}

Macarena Bustamante-Álvarez, mbustamante@ugr.es, https://orcid.org/0000-0001-5988-6908, Universidad de Granada, España. UNIARQ - Lisboa, Portugal

\section{Resumen}

Desde el año 2019 se ha activado un proyecto de investigación cuyo objetivo es conocer el complejo prisma de las marcas de alfareros sobre cerámica, concretamente sobre terra sigillata hispánica. Para ello, como laboratorio de pruebas, se ha optado por recopilar todos los sellos localizados en la provincia más occidental de Hispania, la Lusitania.

En la actualidad se han recopilado más de 1500 marcas diseminadas por esta provincia que nos permite plantear algunas respuestas de corte tipológico, antroponímico y económico sobre este fenómeno. Una vez concluida la primera fase de análisis pudimos comprobar el impacto que sobre esta producción tuvieron las marcas epigráficas externas pre cocturam. Mayoritariamente, este fenómeno afectó a la producción decorada y a un selecto grupo de alfareros procedentes en su amplia mayoría de los talleres de La Rioja así como del taller lusitano de Caesarobriga. Por ello, se decidió aislar estas piezas con el fin de hacer un estudio más preciso sobre las mismas que sirviera de referencia para el estudio en otros puntos peninsulares.

Además de un estudio epigráfico y morfológico de estos sigilla, se aborda una autopsia estilístico que permita, por un lado, dar una respuesta a este singular fenómeno y, por otro, plantear una posible asociación formal entre motivos y alfareros. Aprovechamos también la ocasión para plantear un rápido recorrido historiográfico que nos ha ayudado a unificar las marcas conocidas hasta el momento en suelo peninsular. Con todo ello, se presenta un estudio de síntesis hasta el presente no desarrollado que esperamos sirva de base metodológica para futuras investigaciones.

Palabras claves. Sigillata hispánica; marcas externas epigráficas; producción decorada; Lusitania.

\begin{abstract}
A research project has been active since 2019, with the aim of understanding the complex prism of potters' stamps on ceramics, specifically on Hispanic samian ware. In order to achieve this, as a testing laboratory, we have chosen all the stamps located in the westernmost province of Hispania, Lusitania.

Currently, more than 1500 scattered stamps have been collected in this province, which allow us to propose some typological, anthroponymic and economic responses about this phenomenon. Once the first phase of the analysis concluded, we were able to verify the impact that the pre cocturam external epigraphic marks had on this production. For the most part, it is a phenomenon in decorative productions and in a select group of potters, mainly from the Rioja workshops, as well as from the Caesarobriga lusitanian workshop. For this reason, we decided to isolate these pieces in order to study them more precisely, which would be a reference for the analysis in other peninsular points.

In addition to an epigraphic and morphological analysis, a stylistic analysis of these sigilla is also carried out, which gives an answer to this singular phenomenon and proposes a possible formal association between motifs and potters. We also take the opportunity to propose a quick historiographic journey that has helped us in the unification of the brands known so far in the peninsula. With all these elements, we present a synthesis study that we hope will serve as a methodological basis for future research.
\end{abstract}

Key words. Hispanic samian ware; epigraphic external marks; decorated production; Lusitania.

Financiación: Este trabajo es resultado del proyecto Corpus Vasorum Hispanorum. Analisis tipológico, cronológico y prosopográfico de los sigilla en terra sigillata hispanica a partir de los centros consumidores. Parte I: Lusitania (PGC2018-093478-A-I00 - Convocatoria Proyectos de Excelencia - Plan Estatal de Generación de Conocimiento - Ministerio de Ciencia, Innovación y Universidades - España así como del proyecto Aplicación de nuevas tecnologías para el desarrollo del Corpus Vasorum Hispanorum. Una herramienta para análisis tipológico, cronológico y prosopográfico de los sigilla en Terra Sigillata Hispánica - Programa Logos - Fundación BBVA y Sociedad de Estudios Clásicos. 
«Quali sono le funzioni dei bolli sulla terra sigillata? Se dovessi essere totalmente sincero, dovrei rispondere un puro e simplice: non lo sappiamo».

(Pucci, 1993: 73)

\section{INTRODUCCIÓN}

Se presenta un conjunto voluminoso de 56 sigilla externos en terra sigillata hispánica diseminado en lo que fue la antigua provincia de la Lusitania. Estas piezas se han recopilado al amparo de un proyecto de investigación que atiende a las marcas de alfarero sobre esta categoría cerámica localizadas en la provincia más occidental de la Hispania romana y, actualmente, depositadas en diversos museos tanto en Portugal como en España. Dentro de este proyecto, aunque mayoritariamente se han compilado marcas internas asociadas a las formas lisas, también se han registrado otras externas en un número sensiblemente superior al inicialmente esperado ya que, a tenor de lo hasta el momento publicado, fue un fenómeno muy restringido.

El análisis de estas marcas externas nos abre un nuevo abanico de posibilidades para valorar los diversos estilos decorativos asociados a los alfareros implicados, así como su posible alcance a efectos organizativos en los centros productivos, no sólo en lo que se refiere a su estructura interna sino, de igual modo, en lo que atañe a la definición de su mercado. Además, por todos es consabido que las producciones cuyos sellos ya cuentan con corpora tipológicos sistematizados -caso de la itálica o gálica- son una herramienta de primer orden para conocer el origen preciso de la pieza, así como para aportar datos cronológicos muy concretos.

Las marcas que centran este trabajo, las externas o intradecorativas, aunque ya se conocen ejemplares publicados de antiguo, se articulan como una rara avis

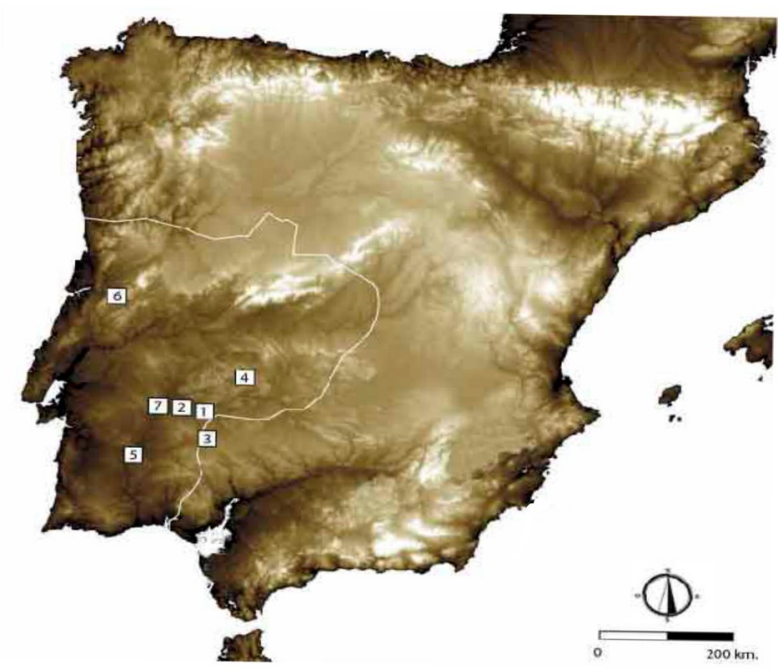

Figura 1: Mapa con delimitación de la provincia Lusitania y procedencias de las piezas que se analizan: 1.- Emerita Augusta; 2.- Lobón (Badajoz); 3.- Hornachos (Badajoz); 4.- El Saucedo (Talavera la Reina, Toledo); 5.- Beja (Portugal); 6.- Conimbriga (Condeixa la Velha, Portugal) y 7.- Talavera la Real (Badajoz) en suelo peninsular y, hasta el momento, no se había planteado una recopilación de este calibre que permita reflexionar sobre este fenómeno tan singular.

En las siguientes páginas, además de plantear un análisis tipológico, iconográfico, antroponímico y epigráfico se vuelca una reflexión de tipo teórico sobre este fenómeno que no quedó recluido, ni geográficamente a la producción peninsular, ni cronológicamente a la época altoimperial. Para ello se plantea una pequeña exégesis sobre la práctica del marcado externo pre cocturam basándonos fundamentalmente en las producciones del Norte -especialmente de Tricio- ya que son las que mayoritariamente afectan al arco geográfico que abarca este estudio. De igual modo, también traemos a colación tres piezas que proceden de la conocida villa del Saucedo y que presentan unas características concretas muy especificas que parecen asociarse al único centro productor de sigillata perfilado, hasta el momento, en lo que fue la provincia de la Lusitania, Caesarobriga (Talavera la Reina) ${ }^{1}$ (Fig. 1).

Al hilo de esta reflexión y teniendo presente la asociación de marcas epigráficas con motivos decorativos también se diseña una primera aproximación a los estilos ornamentales de algunos de los alfareros más fecundos de la península ibérica como fueron Sempronius, Valerius Paternus, Mas(.) o Lapillus, entre otros. Este trabajo se plantea, por lo tanto, como el germen de una propuesta metodológica para el análisis tipocronológico de este fenómeno peninsular a partir de los centros consumidores.

\section{ASPECTOS METODOLÓGICOS SOBRE LA RECOGIDA DE SELLOS EN EL MARCO DE CORPVS VASORVM HISPANORVM}

El objetivo fundamental del proyecto $\mathrm{CVH}$ era recopilar todas las marcas en terra sigillata localizadas en lo que fue la provincia Lusitana con el fin de obtener datos tipocronológicos y económicos de la producción de sigillata y su distribución en la fachada atlántica peninsular. Este proyecto, que aún se encuentra en fase de ejecución, nos ha permitido abordar la recopilación de una ingente cantidad de piezas no sólo publicadas sino también inéditas que suponen un interesante avance en lo que se refiere al conocimiento de esta manufactura en ámbito hispano.

Para la recopilación de los datos a los que ahora nos enfrentamos, se ha procedido, por un lado, al vaciado de las publicaciones relativas al antiguo territorio de la Lusitania y, además, se ha acompañado de un rastreo de los fondos de prácticamente todos los museos

1. Un primer avance sobre este taller lo dio Juan Tovar (1988) a propósito del análisis de unos instrumentos de alfarero, entre ellos un punzón epigráfico. De manera más reciente, esta hipótesis de trabajo se ha afianzado a partir de los datos aportados por la arqueometría (del Hoyo et al., 2021). 
que contaban con cultura material de época romana en este espacio geográfico. Todo ello se ha volcado en una infraestructura de datos online de libre acceso con una sección gráfica con recursos multimedias con una librería threejs en javascript que permite la visualización en tiempo real de todos los datos incluidos. Además, se acompaña con mapas de distribución georreferenciados que permiten obtener datos sobre su disposición geográfica.

Gracias a una interfaz se puede acceder a todos los datos y realizar búsquedas complejas y cruzadas. La tecnología se sintetiza en un motor de base de datos relacional (MySql, MariaDB o SQLite); el desarrollo de aplicación web front end/ back end desarrollado en $\mathrm{php} / \mathrm{html} / \mathrm{css}$ y tipografía latina a partir de un front space específico diseñado en colaboración con los epigrafistas que nos permita el análisis de las formulaciones epigráficas. Una vez volcadas todas las piezas se produjo, gracias al sistema al que hemos hecho alusión, la búsqueda concreta de los ejemplares con sellos intradecorativos al contar con la información específica de cada uno en las máscaras diseñadas a tal efecto ${ }^{2}$.

La simple inclusión de estas piezas en esta base de datos ha aportado información de alto interés para el desarrollo de este trabajo. La distribución, frecuencia de aparición, soportes tipológicos, repertorio decorativo, entre otros, son datos de fácil consulta que permiten ver el interés de este tipo de aplicaciones para un volumen de piezas tan amplio como al que nos hemos enfrentado en un proyecto de este calibre.

Como es consabido, los sellos en sigillata hispánica pueden aparecer o bien en el fondo o bien formando parte del entramado decorativo que adereza algunas de las piezas del repertorio ${ }^{3}$. Sin embargo, frente a la abrumadora presencia de sellos en los fondos interiores de los recipientes, su inclusión en el repertorio decorativo es relativamente menos frecuente. De hecho, en el conjunto recopilado hasta el momento para la Lusitania no llegan al 3\% de la muestra lo que nos habla del escaso impacto del fenómeno.

Sin embargo, a la hora de abordar nuestra investigación hemos podido reflexionar sobre otras posibles causas que aporten datos sobre si la escasez de este fenómeno radica en la frecuencia de esta práctica en los centros productores o más bien en el devenir historiográfico e investigador posterior. Por ello debemos valorar estas dos variables:

- En primer lugar, en muchas ocasiones los sellos externos terminan pasando desapercibidos dentro

2. Dicha base de datos puede consultar on line en la siguiente dirección https://demo.threedcloud.com/CVH/

3. Este es el esquema que, al menos, se atisba en la producción hispana. No hay que olvidar que en la manufactura gálica también se localizan marcas externas que no necesariamente se encuentran dentro del discurso decorativo, sino que aparecen en las franjas lisas que se ubican por encima o por debajo de los frentes decorados. de la amalgama decorativa. De hecho, algunas letras en sí misma parecen motivos ornamentales. Esto hace que sólo a partir de autopsias más concretas, como la que ahora presentamos, podamos percibir estos elementos. Esto dista bastante de lo que ocurre con los sellos sobre las piezas lisas que se visualizan con facilidad.

- En segundo lugar, viene de la propia técnica usada por los alfareros para imprimir estos sellos. Concretamente, estas marcas se estampan directamente sobre los moldes los cuales presentan un doble hándicap, por un lado, tienen un perfil cóncavo que hace que el uso del punzón sea casi «acrobático» $\mathrm{y}$, por otro, la plasmación no es directa en la pieza -como ocurre con las formas lisas- sino que termina siendo retrógrada dificultando la lectura.

Por todo ello, a pesar de que esta práctica no fue muy extensa, creemos que el volumen de piezas que presentan sellos es sensiblemente mayor a lo que, inicialmente, la investigación ha creído.

\section{SOBRE EL FENÓMENO DEL SELLADO (IN- TRADECORATIVO) EN LA PRODUCCIÓN DE SIGILLATA HISPÁNICA}

Uno de los elementos más característicos de la sigillata, aunque no extrapolable a todas las piezas, es la presencia de marcas de alfarero. Estas señas, denominadas comúnmente como sigilla, son signos epigráficos o anepigrafos que, presumiblemente, aluden al componente humano que participó en su manufactura. Esta práctica no fue exclusiva de estas producciones, de hecho, ya en la cerámica griega de época clásica fue habitual la presencia de epígrafes que aludían nominalmente a algunos de los agentes del proceso -o bien alfarero o bien pintor-. Entre el periodo griego y el mundo romano propiamente dicho desaparecen mayoritariamente estas marcas. Este hecho, según Carandini (1979: 130), radica en la presencia de mano de obra esclava que no dejaba rastro epigráfico.

Los inicios de este fenómeno en el arco centro mediterráneo son sensiblemente distintos y parece que estuvieron íntimamente vinculados con la situación política que se vive en el siglo I a. C. A ello hay que unirle el influjo de los movimientos de colonización que favorecía que algunos de los artesanos del barro quisieran dejar patente su origo y filiación -preferiblemente itálico-(Morel, 1976: 269). Esta práctica epigráfica, sin embargo, quedó fuera del alcance de la clase política y militar tras una serie de prohibiciones planteadas por el plebiscito claudiano del 218 a. C. No será hasta el 59 a. C. con la lex Iulia de Repetundis cuando se produce el final de algunas de estas prohibiciones relativas a la presencia de epígrafes de personajes públicos y militares. Es en ese momento cuando comienzan a aparecer los primeros sigilla sobre la producción itálica que aluden a algunos legados militares del triunfante 
Cneo Pompeyo Magno como Quintus Afranius, Caius Valerius o Caius Septimius (OCK 51, 275 y 1872)-para más dato sobre la problemática ver Pedroni, 1995-. Sin lugar a dudas, la presencia de estas marcas alusivas a estos generales triunfantes no parece ser algo casual, sino que quizás forma parte del marketing por captar la atención de los compradores o bien de comenzar una empresa de corte público-militar.

La gran eclosión de este fenómeno viene de la mano de la producción gálica, claramente, vinculada a una manufactura que, anacrónicamente, podríamos calificar como de «industrial» y cuya estandarización alcanza cotas hasta el momento desconocidas. Este modelo, bien estudiado en la Graufesenque, permite hablar de unos medios de producción limitados y de carácter comunal que pudieron precisar de unas marcas que ayudaran a reconocer la producción (Danell, 2002). Esta práctica parece decaer avanzada la época antonina por la apertura de una serie de talleres que podemos calificar como «familiares» y que supuso la tenencia y autogestión de los medios de producción. Por consiguiente, en este nuevo modelo, plasmar estas marcas identitarias carecería de sentido.

Para la producción hispana, la marcación ha gozado de buena salud tanto en las producciones de corte precoz como la hispana propiamente dicha. Sin embargo, el fenómeno del marcado sigue generando algunas dudas sobre su posible praxis y parece que termina quedando reducida su aplicación a formas muy concretas (Pucci, 1993: 74) y recurrentemente asociable a las piezas más comunes del repertorio comercializado fuera de los límites del alfar.

Estas señas se pueden dividir en dos grandes grupos en función de su naturaleza, o bien epigráficas o bien anepígrafas y, a su vez, en dos grandes apartados en relación al lugar donde se plasman, o bien en el fondo interior de las piezas o bien formando parte de su repertorio decorativo. Independientemente del lugar o el modo de plasmarlo todas comparten una característica común: son hechas pre cocturam.

En relación al lugar donde se posicionan, mayoritariamente, se ubican en el fondo interior de las piezas. El éxito de esta práctica radica en ser el sitio donde más fácilmente el alfarero puede maniobrar con el punzón ya que es una zona relativamente plana en la que puede contar con el espacio suficiente para «despegar» el instrumental de la masa fresca ${ }^{4}$. Esto, además, puede llevar consigo un hándicap cual es una cierta falta de estandarización a la hora de sellar las piezas ya que es el alfarero, en el mismo momento de estampar,

4. Los punzones que conocemos con nombres de alfareros, aunque escasos, nos permite definir dos categorías concretas por un lado aquellos hechos en soporte cerámico caso del localizado en Talavera de la Reina o bien en madera como se ha podido definir al analizar la importa de un sigillum en Haltern (von Schnurbein, 1982: 65, Abb. 16). También hay algunos autores que apuestan por el sobremodelado de sellos (Hartley, 1977). quien decide dónde ubicar la marca pudiéndose dar problemas de centralización del sello con respecto al eje central de la pieza. De igual modo, esta plasmación directa, sin ninguna «interfaz» intermedia -como puede ser el molde-, podría ayudar a plantear posibles planes de contingencia ante plausible errores -como la impresión parcial- siendo esto fácilmente solventable con el alisado de la superficie y la nueva impresión.

A todo lo indicado hay que unirle que es el único lugar donde se conseguiría que, sin mover la pieza de su posición natural, el campo visual del usuario fuera capaz de percibirlo. Esto, además, se intensifica en el momento que se usase la pieza y se vaciase su contenido permitiendo así un efecto sorpresa al consumidor. Estas ideas, además, se acentúan por el propio análisis de los sellos hasta el momento conocidos ya que no se ha localizado a día de hoy ninguna marca de estas características en su fondo externo ya que pasarían desapercibidas por el usuario, a menos, que se le diera la vuelta a la pieza intencionalmente. Por lo tanto, los recipientes que aparecen sellados en el fondo interior, claramente, tienen como propósito que esos sellos sean vistos por las personas que los usaran.

El otro lugar a ubicar estos sellos sería en medio de sus discursos decorativos y que, tradicionalmente, han recibido el nombre de marcas intradecorativas o externas. En este gran grupo, además de las marcas de alfareros, hay otro conjunto de piezas que presentan fórmulas de saludo, propiciatorias o expresiones usuales que quedan fuera de nuestro estudio por no hacer alusión a su productor $\mathrm{y}$, además, por ser un fenómeno casi ausente en el registro hispano y altamente recurrente en la producción gálica (Genin, 2007).

En el grupo de las marcas externas, el sentido al que anteriormente hemos aludido para el sellado en las piezas lisas necesitaría un serio planteamiento ya que, en esta modalidad, son manufacturadas a partir de un molde que ya tiene impreso el sello por lo que no hay posibilidad de cambiar este esquema en el momento del modelado de la pieza. Además, hay que tener presente que, mayoritariamente, son elementos que terminan pasando desapercibidos ante la maraña decorativa en la que se inserta. Esto, asimismo, se acentúa por su plasmación en una superficie ligeramente curva que forzaría a que el consumidor tuviera que mover la pieza para poder percibir este sello quedando diluido si el recipiente estuviera en su posicionamiento natural, esto es sobre una superficie plana. En este caso, los beneficios a los que anteriormente hemos aludido con el marcado de las piezas lisas, claramente, se pierden. Por un lado, el alfarero de manera premeditada tiene que marcar el molde bien a mano alzada o bien con un punzón. Esto hace que haya una interfaz de plasmación que limita cualquier cambio en el planteamiento originario por lo que no sería posible modificar lo marcado una vez plasmado. Cualquier modificación supondría un cambio del programa decorativo y, posiblemente, la necesidad de volver a moldear la pieza desde un inicio. Esta reflexión nos ayuda a dar respuesta al porqué de 
una gran cantidad de sellos que aparecen sobre piezas decoradas y que, aunque, prácticamente, son ilegibles no se observa ningún plan por parte del alfarero por resolver este problema al ser plenamente consiente de que posiblemente el usuario no se percataría de la presencia de estos signos.

En relación a qué es lo que se plasma, independientemente del sitio donde se ubique, por un lado, pueden aparecer logotipos anepigráficos del taller, el nomen o el cognomen del figulus expresados de manera completa, abreviados o acompañados de fórmulas epigráficas.

Sin embargo, el gran problema que envuelve al fenómeno del sellado sobre sigillata es su motivación ya que es una de las pocas producciones cerámicas que presentan sellado, sin embargo, no todas las piezas en esta categoría lo tienen.

En cuanto a la incitación, son muchos los investigadores que se han acercado a esta problemática sin dar una respuesta plausible y aplicable a toda la producción.

Para algunos autores son simples marcas que indican quién fue el artesano encargado de la manufactura del vaso o bien el titular de la instalación (Polak, 2000). La función vinculada a esta explicación sería la de diferenciar sus manufacturas en talleres comunales donde se comparten espacios como los secaderos o los hornos, permitiendo estas marcas diferenciar la producción, evitar confusiones e, incluso, repartir posibles gastos generados en el marco de una posible locatio-conductio -caso del combustible, agua o el desgaste de las estructuras- (Pucci, 1993: 78). Vinculado con la idea de organización, las marcas también podrían haber ayudado a los responsables del taller a llevar la contabilidad de las piezas manufacturadas por cada uno de los alfareros de la officina y definir, incluso, un arco temporal de las jornadas laborales dentro de estos espacios. Sin embargo, esta hipótesis entra en clara contradicción en el momento en el que se observa que no todas las piezas están selladas. Esta idea quizás se podría solventar si planteamos que la marca aludiera a un signo de contabilidad que supusiera que cada sigilla indicara un número no definido de piezas de similar porte realizadas por un mismo alfarero. Sin embargo, esta teoría para el caso de la sigillata fue desechada por el propio Pucci (1993: 74) afirmando que si sólo se sellase la primera de las piezas de una pila, debería haber menos ejemplares sellados de los que el registro nos aporta.

Otra de las hipótesis que se han barajado es que el sellado no apuntara al alfarero encargado de su manufactura sino al dueño de los medios de producción. Esto, sin lugar a dudas, implicaría una clara jerarquización dentro del taller, algo que se ha podido atestiguar en la producción itálica gracias a la presencia de algunos sellos alusivos a esclavos participantes en los procesos productivos y cuya relación de dependencia queda plasmada por medio del caso genitivo. Esta idea, sin embargo, choca con la presencia de varias marcas en espacios que debieron pertecener a un mismo taller y que, por consiguiente, tuvo un único dueño de los medios de producción. También esto implicaría que los alfareros con medios de producción propios no precisasen de estas marcas (Siebert, 1978) quedando así su implicación silenciada en los vestigios materiales.

Otra idea planteada en el descifrado de estas marcas sería que fueran símbolo de calidad alusivos a ciertos alfareros de gran reputación que incitaran a los consumidores a adquirir estas piezas de alto «renombre». A este respecto, algunas marcas localizadas en la Graufesenque, donde aparece expresamente la frase fecit aretinum o bien los nombres de los alfareros gálicos precedidos de la palabra arretinum, intentan aportar unos índices de calidad al aludir epónimamente al primigenio centro productor -Arezzo- (Ettingler y Fellman, 1955). Sin embargo, esta marca aparece envuelta en una posible falsedad al ser piezas hechas en suelo gálico (Bémont, Vernhet y Beck, 1987; Pucci, 1993: 75). Además, el centro productor de Arezzo estuvo al tanto de esta problemática como se extrapola de la presencia de marcas del tipo Arretinum verum, OCK 244, n. ${ }^{\circ} 1$ (Morel, 1988; Pucci, 1993) donde claramente pone sobre la mesa la presencia de piezas non verum 5 .

Esta idea, sin embargo, también termina difuminándose por el hecho de que los recipientes más complejos, los que presentan decoración, mayoritariamente, no tienen estas marcas. Por consiguiente, estas indicaciones pudieron tener una explicación simplemente para los agentes de la producción.

Independientemente de la función, la gran cantidad de piezas que presentan sellos ha generado que sean múltiples los trabajos que aluden a estos curiosos elementos e, incluso, se han definido corpora de compendio para aglutinar estos sellos. Esta praxis ha convertido estas marcas en verdaderos fósiles cronoculturales. Ejemplo de ello es el CVA, Corpus Vasorum Arretinorum (Oxé y Comfort, 1968; Oxé, Comfort y Kenrick, 2000) o para las sigillatas gálicas el Index of Poters'Stamps (Oswald 1931) o el Names on Terra Sigillata. An Index of Makers 'Stamps \& Signatures on Gallo-Roman Terra Sigillata (Samian Ware) (Dickinson et al., 2008-2016). Para la sigillata hispánica no existe a día de hoy una compilación completa que aúne aspectos tipológicos, cronológicos o prosopográficos como sí ocurre con los corpora antes enunciados. Esto no es óbice para que sí se hayan planteado algunos listados nominales que afectan a los alfareros (caso de Mezquíriz, 1961; Roca y Fernández (Eds), 1999), algunos trabajos que prestan atención a la onomástica de determinados centros productores (Mayet, 1984; Simón Cornago, 2017) o investigaciones que valoran la cronología y tipología de algunas de las marcas (Bustamante-Álvarez, 2013).

El análisis de las piezas con sellos externos ha sido un tema recurrente desde los primeros momentos de la

5. Este mismo caso se podría extrapolar a la producción hispánica con el origo tritiense expresado de manera directa en algunos sellos caso de Segius Tritiensis, Fabius Tritinesis, entre otros. 
andadura historiográfica de la terra sigillata hispánica y pudo ser un fenómeno que tuvo arraigo desde los primeros pasos de las producciones sinterizadas en suelo peninsular. Esto se extrapola al ver cómo algunos de los productores precoces ya marcan las piezas decoradas. Entre ellos tenemos buenos ejemplos como Maternus quien firma sobre forma Drag. 29 (Romero Carnicero, 1984: fig. 3, n. ${ }^{\circ}$ 2) o MCR quien plasma su nombre también sobre la misma forma (Romero Carnicero et al., 2016: fig. 2, n. ${ }^{\circ} 1,8.1$.).

La andadura historiográfica sobre este fenómeno se inicia antes de la misma sistematización tipológica de la producción planteada por Mezquíriz (1961). De hecho, uno de los primeros sellos externos dados a conocer se publicó varios años antes. Concretamente, nos referimos a un conocido ejemplar de Iruña; un fragmento de forma 37 con grafía desarrollada de manera circular, en la que se leyó [.]ONVST[.] -asociado a Titus Sagenus-. La propia inscripción termina siendo una cartela circular que enmarca una flor multipétala en el centro (Nieto Gallo, 1958: 71, fig. 44). Esta pieza, de alto interés, fue de nuevo recogida por otros investigadores (entre otros Mezquíriz, 1961: lám. 7, n. ${ }^{\circ}$ 5; Comfort, 1961: 10).

Podemos decir que el primer gran estudio de compendio sobre las producciones hispanas, así como sus marcas -incluyendo las externas- vino de la mano de Mezquíriz (1961). Esta autora planteaba una interesante reflexión sobre este fenómeno e, incluso, a pesar del reducido número de piezas publicadas pudo dar a conocer algunos de los rasgos básicos de esta práctica (Mezquíriz, 1961). Primeramente, asevera que las marcas externas van parejas a las producciones decoradas siendo un fenómeno extremadamente raro. En segundo lugar, ahonda en su morfología afirmando que se pueden agrupar en dos tipos. Por un lado, aquellas en las que el sello aparece enmarcado en cartucho, algo habitual en los fondos de la producción lisa. Esta práctica aplicada a las paredes de las formas decoradas genera que, mayoritariamente, sean ilegibles. Por otro lado, estarían aquellas letras que se insertan en el discurso decorativo. Y, en tercer lugar, reflexiona sobre cómo el alfarero plasma dichas marcas en los moldes. A este respecto plantea dos posibilidades, bien por medio de punzones prediseñados con letras y usados para la producción lisa o bien a mano alzada. Toda esta deliberación viene al hilo del análisis de un conjunto de piezas entre las que se destacan algunas de Mérida que serán evaluadas al hilo de este estudio-, Pamplona, Iruña, Numancia o Corella (Mezquíriz, 1961: lám. 7). A ello hay que unirle la presentación de uno de los únicos ejemplares de sellado interno sobre piezas decoradas. En concreto, nos referimos a una forma Hisp. 37 con doble registro decorado procedente de Mallén. La parte superior tiene festones semicirculares que se entroncan con círculos y figuras florales centrales. En la parte inferior, el discurso es similar, pero aparecen elementos zoomorfos. En el sello en cartucho rectangular ubicado al interior de la pieza se puede leer EX OF (.) EM (Mezquíriz, 1961: lám. 159, n. ${ }^{\circ} 23$ ).
En este marco cronológico nos parecen de interés las publicaciones que vieron la luz de la mano de Boube (1965; 1966; 1968-1972a; 1968-1972b) y que pusieron sobre la mesa todo el elenco de alfareros hispanos que comercializaron con la Mauretania Tingitana y entre los que se encontraban piezas con marcas externa.

De manera más puntual, Sotomayor (1977) planteó una interesante reflexión centrada en la producción de los talleres de Isturgi perfilando como respuesta al fenómeno de las producciones con marcas externas un posible influjo bifurcado tanto galo como itálico.

La siguiente gran obra de compendio, la de Mayet volvió a poner sobre la mesa la problemática de los alfareros. En este caso presentaba una amplia nómina de ellos entre los que aparecía un abundante repertorio de ejemplares tanto en cartucho rectangular, decoración en friso o, incluso, dos piezas decoradas con sello al interior, ambas procedentes de Mallén. De nuevo, esta autora plantea la rareza de este fenómeno, sobre todo, al centrarse en las producciones del norte ya que, por el contrario, los talleres del sur gozaban de buena salud -aunque «marginal»sic- en lo que al marcado externo se refiere. Con la nómina de tipos que ella compila define tres grandes grupos: las marcas en cartucho rectangular, las letras aisladas o bien los nombres desarrollados intradecorativamente (Mayet, 1984). De manera puntual, además, trata las producciones de Andújar cuyas letras pueden ocupar todo el friso y, en algunas ocasiones, presentan la particularidad de ser inscripciones con trazos bifoliáceos. Sin embargo, en su discurso plantea una clara diferenciación entre las letras sueltas y los nombres desarrollados o en cartucho. En el caso de las letras, su reflexión se incluye dentro del apartado destinado al estudio de las producciones decoradas por lo que no las define plenamente como marcas de alfarero (Mayet, 1984: pl. CCVII).

Junto a estos trabajos que han marcado claramente la investigación de las producciones hispanas y, más concretamente, las piezas con marcación externa, debemos unir el estudio planteado por Mezquíriz (1985) dentro del Atlante delle Forme Ceramiche donde actualiza el elenco de alfareros y presenta algunas formas decoradas con nuevas marcas externas. De manera más reciente, la actualización de sellos de los talleres de La Rioja ha sido hecha por Sáenz y Sáenz (1999) que sirve como base para la revisión que ahora planteamos.

A toda esta nómina de trabajos de compilación es preciso unirle un conjunto de publicaciones que, de manera puntual, aun no abordando de modo específico la problemática de las marcas externas, recogen algunos ejemplares. Para ello en las siguientes páginas planteamos un rápido recogido de las marcas externas localizadas en la producción de sigillatas norteñas. Para ordenar este listado optamos por agrupar por alfareros y definir el elenco por orden alfabético o bien por el nomen -si hubiera más partes diagnósticas- o por la primera letra/vocal de la parte que se conserve. 


\subsection{EJEMPLOS DE SELLADOS INTRADECORATIVO. RECO- RRIDO HISTORIOGRÁFICO}

El primer alfarero de esta extensa nómina sería Annius, cuyo centro productor se ha fijado en Arenzana de Arriba (La Puebla). De este artesano se ha localizado un ejemplar de forma Hisp. 37 con composición, posiblemente, metopada. En ella aparece un felino que formaría parte de una escena de venatio. En medio de la representación se observan las letras a mano alzada en la que se lee ANIVS (Garabito, 1978: 457, n. ${ }^{\circ} 1$ y lám. 96, n. ${ }^{\circ}$ 1; Mayet, 1984: pl. CCVIII, n. ${ }^{\circ}$ 47; Mezquíriz, 1985: 121$)^{6}$.

El siguiente artesano con similar nomen sería [.] Anno In [. $]^{7}$ del que hemos localizado dos ejemplares de forma Hisp. 29 procedentes de Bilbilis $^{8}$. El primero es un perfil bastante desarrollado de esta forma en el que en el friso superior aparece la inscripción [.]S·ANNO·IN[.] y en la inferior se localiza un ave (Mayet, 1984: pl. CCVII, n. ${ }^{\circ}$ 2600; Sáenz Preciado, 1997: 559-560, n. ${ }^{\circ} 40$ y lám. 84, n. ${ }^{\circ}$ 573; 2018: 296, n. $\left.{ }^{\circ} 40-41\right)$. El segundo, corresponde a un galbo con composición muy similar. Esta pieza tiene el mismo discurso decorativo a excepción de la representación zoomorfa inferior donde, en esta ocasión, aparece un cánido. En el fragmento de marca conservado leemos [.]NNO·IM[.] (Sáenz Preciado, 1997: 559-560, n. ${ }^{\circ} 41$ y lám. 84, n. ${ }^{\circ}$ 574).

El siguiente alfarero que selló externamente sus producciones es $A S T[$.$] . La única pieza conocida pro-$ cede de Mérida, sin embargo, al hilo de este estudio no se ha podido localizar físicamente. Además, indicar que los dos trabajos que lo abordan aportan dos representaciones graficas sensiblemente distintas y, por consiguiente, dos lecturas disímiles. En primer lugar, Mezquíriz apuntó a [.]OTAO[.] (1961: lám. 7, n. ${ }^{\circ}$ 8) mientras que Mayet (1984: pl. CCVIII), posiblemente analizando el fragmento de manera directa, apostó por el alfarero $A S T[$.$] . Esta última autora describe la deco-$ ración que acompaña al sello como una composición metopada con líneas onduladas verticales.

Uno de los alfareros más prolíficos en lo que se refiere al marcado externo es el, tradicionalmente, denominado como VLLO (Romero Carnicero, 1978) y

\footnotetext{
6. Interesante resulta también la presencia de sellos rectangulares sobre moldes de formas decoradas pero que, desgraciadamente no dejan evidencias en la pieza en positivo. Un caso de resaltable sería la del alfarero Annius Martialis (Sáenz Preciado, 1994: 94, n. ${ }^{\circ}$ 3-4, lám. 5, n. ${ }^{\circ} 30-31$ ).

7. Hay un ejemplo con mayor desarrollo el localizado en La Cereceda que plantea la posibilidad que la última parte sea IM[.] (Sáenz, 2018: 286).

8. Al igual que ocurre con el sello [.]BO[.] esta marca difiere del resto por tamaño de letra así como su ubicación en el vaso. Se podría valorar, aunque a día de hoy no conocemos ejemplos en la producción hispana, la posibilidad de estuviéramos ante fórmulas de saludo o propiciatorias al igual que ocurre con otras producciones de sigillata.
}

que un reciente estudio, de manera acertada, ha «rebautizado» como ATTO (Romero Carnicero, 2020). Este alfarero procede de los alfares de Uxama. Esta hipótesis del cambio de nombre se basa en la posible práctica epigráfica consistente en escribir de manera retro/invertida aderezada por la presencia del molde que actúa como interfaz. Entre los ejemplares más sobresalientes se encuentran tanto las piezas con sellos a mano alzada, caso de la de Numancia (Mezquíriz, 1961: lám. 7, n. ${ }^{\circ}$ 6; Mayet, 1984: pl. LXXXIX, n. ${ }^{\circ}$ 343-345 y 351-352; Romero Carnicero, 1985: fig. 16, 112, 116-117), como aquellas que se presentan sobre cartucho cuadrangular. Algunos de los puntos donde se localizan ejemplares de este tipo serían Arcobriga (Juan Tovar, 1992: fig. 1.3.13, n. ${ }^{\circ}$ 149), Alcalá de Henares (Fernández Galiano, 1976: 75, lám. 34), Complutum, Valeria y Segobriga (Sánchez Lafuente 1990), Bilbilis (Sáenz Preciado, 1997: 552-553, n. ${ }^{\circ}$ 37, lám. 64, n. ${ }^{\circ} 447$; 2018: 295, n. 24 ), Lixus (Boube, 1965: 119, tab. 15), Numancia (Romero Carnicero, 1985: 280 y ss.) entre otros (para más información y sobre la dispersión actualizada ver a Romero Carnicero, 2020: fig. 1).

El siguiente alfarero del que, desgraciadamente, no podemos plantear su desarrollo completo sería [.]Bo[.]. Hasta el momento se ha encontrado un único ejemplar procedente de Bilbilis. La pieza presenta su registro superior con decoración de metopas quebradas que enmarcan un elemento floral central. En el friso inferior aparecen las letras a las que hemos hecho alusión (Martín Bueno, 1976: 114, lám. XIII, n. ${ }^{\circ}$ 15; Mayet, 1984: pl. CCVII, n. o 2601; Sáenz Preciado, 1997: 560, n. 43 y lám. 148, n. ${ }^{\circ} 946 ; 2018$ : n. $\left.{ }^{\circ} 42\right)$.

El siguiente alfarero (.)EM selló una pieza localizada en Mallén (Mezquíriz, 1961: lám. 159, n. ${ }^{\circ}$ 23). Presenta el interés específico de ser una de las únicas formas decoradas que cuentan con sellado interno. Esta forma Hisp. 37 tiene una composición en doble registro con decoración de festones y arcadas. En el sello en cartucho interior podemos leer EX OF (.)EM.

Del posible alfarero (.)ERO, también tenemos un sello interior en una forma Hisp. 37 con composición metopada muy compleja dividida en tres registros decorativos. De interés resulta que también proceda de Mallén (Mayet, 1984: pl. CIV, n. $\left.{ }^{\circ} 427\right)^{9}$.

Continuando con la nómina de artesanos, tenemos al figulus Festus. El único ejemplar hallado es una forma 29 procedente de la necrópolis de Sala en Marruecos. En dicho sello se puede leer FEST (retro) (Boube, 1968-1972b: index).

Del alfarero Flavus tenemos un ejemplar localizado en Gerona con decoración con doble registro. En el inferior aparecen círculos concéntricos múltiples y en el superior, la decoración metopada se encuentra delimitada por bastones quebrados y bifoliáceos que

\footnotetext{
9. Interesante resaltar como Mezquíriz (1961: lám. 152, n. o 26) publica la misma pieza, sin embargo, no se hace eco de este sello.
} 
enmarcan figuras zoomorfas. El sello aparece en cartucho rectangular y se puede leer FLAVO retro (Mayet, 1984: pl. CXIV, 477).

Del alfarero [.]FM[.], nos hacemos eco de un fragmento de Hisp. 29 con friso corrido inferior, mientras que en la parte superior aparecen las letras impresas [.] $\mathrm{F} \cdot \mathrm{M}[$.$] . El único ejemplar hasta el momento localizado$ procede de Bilbilis (Mayet, 1984: pl. CCVII, n. ${ }^{\circ} 2598$; Sáenz Preciado, 1991: lám. 84, n. ${ }^{\circ}$ 575). Recientemente Sáenz Preciado (2018: 296, n. ${ }^{\circ} 42$ ) lo ha reinterpretado como [.]FC[.].

Una pieza de interés sería la localizada en Argote (Burgos) en donde se advierte una composición metopada con líneas bifoliaceas y separadores quebrados. En el centro de la metopa, aparece felino en movimiento. Bajo el animal se localiza un sello en cartucho rectangular con inscripción retro donde se lee INA.MA (Acuña y Elorza, 1974: 166, fig. 2). Otro sello que asociamos al mismo alfarero sería el localizado en Lugo donde, además del esquema decorativo, encontramos un cartucho con similares letras (Carreño, 1997: fig. 21, n. ${ }^{\circ}$ 94).

De Iurius Anc [.] contamos un ejemplar sobre una forma Hisp. 29 con decoración metopada a partir de líneas bifoliáceas y motivos imprecisos en el centro de la representación. En la parte superior, aparece la inscripción IVRANC (Comfort, 1961: 10 y fig. 9, Mezquíriz, 1961: 240 cita a partir de Sáenz y Sáenz, 1999: 105; 1985, 128, n. ${ }^{\circ}$ 141; Mezquíriz, 1985: 128). Aunque su depósito aparece recogido en la Universidad de Salamanca, se indica expresamente su procedencia del levante peninsular.

El siguiente alfarero en este elenco sería Lucius Iunius(.) del taller de Los Pozos en Tricio. De este alfarero tenemos un ejemplar en el que se lee LV·IVN (retro) procedente del Museo de Logroño (Mayet, 1984: pl. CCXIII, n. ${ }^{\text {o } 320) . ~}$

De Lupianus de Tricio tenemos un ejemplar sobre forma Hisp. 37b procedente de Segobriga (Sánchez Lafuente, 1990: 39).

Del centro productor de La Cereceda (Arenzana de Arriba), se conocen varias marcas intradecorativas de diversos alfareros. El primero en este elenco alfabético sería Luteus. De este se ha localizado una forma Hisp. 37 con decoración metopada a partir de líneas onduladas y representación de biga en la parte central. Toda la escena está delimitada por una cenefa de bifolíaceas y la marca epigráfica, a mano alzada, culmina la representación central (Mezquíriz, 1985: 130; Sáenz Preciado, 1994: 85, lám. 4, n. ${ }^{\circ}$ 28).

De Manlius Maternus Tritiensis se localizan dos ejemplares. Uno procede de Castrojeriz con decoración a círculos concéntricos sogueados e inscripción de tendencia circular que enmarca un motivo redondo en su interior (Abásolo, 1976-1977; Mezquíriz, 1985). El otro ejemplar, aunque dudoso como sus investigadores plantean, procede de Calzadilla de la Cueza (de Castro, 1975). Con similar nomen encontramos a Maternus Viuli con un ejemplar en Fonte do Melho,
Portugal (Russel Cortez, 1951; Mezquíriz, 1985) o a Maternus Tritiensis con un ejemplar en León (García Marcos, 1990: n. ${ }^{\circ}$ 19).

El siguiente artesano en la nómina sería el tritiense Miccio del que tenemos un ejemplar sobre forma Hisp. 37 localizado Cotta donde se puede leer OF-MICCIONIS (Boube, 1965). De este mismo artesano tenemos un ejemplar procedente de Cástulo sobre un gran recipiente de la forma Hisp. 37 con decoración metopada y escenas de venatio. Dentro de una de las metopas y culminando la escena aparece el sello MICCIONIS (Almagro y Caballero, 1968-1972; Mayet, 1984: pl. CI, n. ${ }^{\circ}$ 419). Para finalizar traer a colación un posible ejemplar de este alfarero procedente de Ilici dentro de una composición con escena de venatio, un recurso iconográfico muy utilizado por este alfarero (Montesinos, 1991: n. ${ }^{\circ}$ 49).

Un alfarero del que pocos datos podemos aportar es $R O M$ [.] o RAM[.] cuyo único ejemplar conocido procede de la necrópolis de Pere Martell en Tarragona (Mayet, 1984: pl. CCVII, n. ${ }^{\circ}$ 2601).

Al contrario que el escasamente representado alfarero que hemos hecho alusión en el párrafo precedente, tenemos al ampliamente conocido Segius Tritiensis. De este artesano se ha localizado un posible ejemplar sobre forma Hisp. 37 procedente de Arcobriga (Juan Tovar, 1992: 74, n. ${ }^{\circ} 13$ y fig. 1.3.25, n. ${ }^{\circ} 234$ ). La decoración presente es metopada a partir de líneas bifoliaceas. Las únicas dos metopas que son perceptibles en esta pieza nos permiten analizar, por un lado, una figura antropomorfa y, por otro, letras a mano alzada en la que se puede leer SII ( $\mathrm{s}$ invertida). En el elenco que presentamos en este trabajo aparece otra pieza con similar sello $y$, para la cual, planteamos otra posible interpretación que veremos en apartados venideros.

Una pieza estudiada de antiguo sería la recogida por Comfort (1961) procedente de Julibriga en la que se lee SIG[. ] A[. ] del que pocos datos podemos aportar ya que no quedó recogido gráficamente por este autor.

El alfarero Titus Sagenus es otro de los artesanos más proclives en la plasmación de marcas externas. En concreto, se observa una cierta estandarización de su sello. Las dos partes de su nombre aparecen separadas por una hédera. El formato circular de la inscripción permite definirse en sí misma como una cartela que suele delimitar una figura de anátrida. Los ejemplares de este figulus son múltiples entre los que se destacan los de Bílbilis (Sáenz Preciado, 1997: 553-554, n. ${ }^{\circ} 38 ; 2018$ : 296, n. ${ }^{\circ} 38$ ), Complutum (Sánchez Lafuente, 1990: n. ${ }^{\circ}$ 315, n. 35-36), Ilerda (Pérez Almoguera, 1990: 106107, n. ${ }^{\circ} 801$ ), Iruña (Nieto Gallo, 1958: 71, fig. 44; Comfort, 1961: 10; Acuña y Elorza, 1974: 161), León (García Marcos, 1990: n. ${ }^{\circ}$ 37), Numancia (Mezquíriz, 1961: lám. 7, n. o 3; Mayet, 1984: pl. CCXIX; Romero Carnicero, 1984: 175, n. ${ }^{\circ}$ 708), Cotta (Boube, 1965: 121d, lám. XVI y fig. 22), Lixus (Boube, 1965: 122E, fig. 22), Padilla del Duero (Romero Carnicero, 1986: 238, n. ${ }^{\circ}$ 6) o Salvatierrabide -Álava- (Acuña y Elorza, 1974: 160-161). 
Con similar nomen al anterior alfarero tenemos a Titus ${ }^{10}$ Sempronius. Este alfarero ubicó el taller de Los Morteros de Bezares. El ejemplar con marca externa intradecorativa procede de Velilla del Ebro (Sáenz y Sáenz, 1999: 128).

Continuando con el repaso de los alfareros analizamos la figura de Tanus. Únicamente, tenemos una pieza procedente de la colección Reprezas (sita en Beja). Es una Hisp. 37 con decoración a círculos concéntricos con cartucho rectangular en el que se puede leer el sello OFTANI (retro) (Mayet, 1984: pl. CCXIX, n. ${ }^{\circ}$ 629) ${ }^{11}$. De este último alfarero podrían ser los ejemplares asociados artesano T[.] VS[.] con piezas recogidas en Tricio (Garabito, 1978: 319 a partir de Sáenz y Sáenz, 1999: 129) y en Banasa (Boube, 1965; Mezquíriz, 1985).

Por su excepcionalidad a la hora de firmar destacamos a Valerius Matrianus (Sáenz y Sáenz, 2015). Concretamente, este alfarero del alfar de La Cereceda firma en el baquetón de unión entre los dos frisos decorativos de la forma Hisp. 29. El primero de los ejemplares, en el que se puede leer OFI-VALERI MATRANI (retro), presenta decoración metopada de extrema complejidad con bastones florales, círculos concéntricos, arcadas, festones, así como posibles esquematizaciones de insignias militares (Sáenz y Sáenz, 2015: 164, fig. 2). La segunda pieza, con doble composición también metopada y pseudometopada, presenta animales diversos que compagina con bastones, líneas bifoliaceas así como líneas perladas. En este caso, la marca aparece retro e invertida y se puede leer MATRANI (Sáenz y Sáenz, 2015: 164, fig. 4). El último ejemplar presenta también decoración metopada con márgenes limitados por bifoliaceas. En este alfarero se observa cómo la inscripción, claramente, se plasma una vez que la composición está definida como se saca de conclusión al pisar las letras algunos motivos. Interesante resulta el hallazgo de una serie de fragmentos que presentan en el mismo sitio una inscripción alusiva a Domiciano acompañado de la palabra «forma». A este respecto algunos autores han valorado esta inscripción como «molde del emperador Domiciano» (Sáenz y Sáenz, 2015), sin embargo, un estudio epigráfico más profundo intenta asociar la inscripción al hecho de que la palabra «forma» acompañase al nombre de un alfarero a tenor de los paralelos localizados en otros centros productores, no necesariamente hispanos (Simón, 2020).

Del alfarero estrella por antonomasia en los centros consumidores lusitanos, Valerius Paternus, tenemos también ejemplares con sellos intradecorativos. Concretamente, contamos tanto marcas a mano alzada como motivos hechos a punzón (Mezquíriz,

10. Recordemos que Titus es un nomen patronímico cuyo origen pudo ser el del praenomen Titus. En este caso lo tomamos como nomen.

11. Esta pieza en la actualidad se encuentra en paradero desconocido.
1961: lám. 7, n. $\left.{ }^{\circ} 1-2 ; 1985\right)$. Un ejemplar que podría localizarse dentro de la esfera de este ceramista sería una forma Hisp. 29/37 de Numancia. En esta pieza, en una composición metopada con bastones verticales quebrados y bifoliáceos con figuras zoomorfas, aparecen las letras AP sueltas vinculables a este prolífero alfarero (Romero Carnicero, 1984: 99, fig. 28, 274). En este mismo enclave también se localizó un fragmento de Hisp. 37 con decoración de círculos concéntricos sogueados con figura floral multipétala en el centro y separadores vegetales verticales. Entre dos de las cartelas circulares y dando la sensación de ser un motivo vertical, a modo de separador, aparece un ejemplar de sigillum en cartucho rectangular en el que se lee (.) XOFVA.PAT (retro) (Mayet, 1984: pl. CXV, n. ${ }^{\circ} 483$; Romero Carnicero, 1985: fig. 56, n. $\left.{ }^{\circ} 550\right)$. Dentro de las posibles marcas externas, hay una muy significativa al articularse como un motivo en $\mathrm{V}$, bien en composición corrida con círculos concéntricos o bien a partir de la combinación de dichos motivos con erotes que terminan actuando como separadores (Garabito, 1978: fig. 76, n. $^{\circ} 115$ y 116) que nos hablarían de una versatilidad a la hora de plasmar las firmas. De Valerius Paternus también tenemos una posible asociación con el alfarero Mas, cuya pieza, de nuevo, traemos a colación en este estudio (Mezquíriz, 1961: lám. 7, n. ${ }^{\circ}$ 3; 1985: 141).

Una posible variante de este alfarero riojano sería $V[] P L.[$.$] del que se conoce un ejemplar procedente$ de Conimbriga (Comfort, 1961: 10, fig. 10) y del que luego aportaremos más señas.

Del siguiente alfarero, PAT NAB se localiza un ejemplar de sello sobre cartucho rectangular procedente de Numancia con decoración metopada con escenas zoomorfas y geométricas en el friso inferior. En el friso superior, las metopas se complejizan con la presencia de pseudoarcadas con elementos bifoliáceos (Mayet, 1984: pl. CXII, n. ${ }^{\circ}$ 461).

Para ir concluyendo con este elenco traemos a colación el otro alfarero significativo de La Cereceda (Arenzana de Arriba), Caius Valerius Verdula (Sáenz Preciado, 1994: 90-92, n. ${ }^{\circ}$ 32-33, lám. 4, n. ${ }^{\circ}$ 29). Este artesano presenta la particularidad de firmar dos veces su vaso. Por un lado, de manera desarrollada a mano alzada y, por otro, a partir de cartucho en tabula ansata a punzón donde plasma sus iniciales CVV. Ambos sellos aparecen en el mismo friso decorativo acompañando una composición corrida de motivos indeterminados. De interés resulta la posible creación de una sucursal de este alfarero en otros puntos peninsulares (caso de Calagurris) y la proliferación de su producción a otras categorías cerámicas caso de las paredes finas así como producciones engobadas (Sáenz Preciado, 1994).

Junto a este recorrido que hemos hecho de los principales alfareros que sellan externamente piezas debemos unirle algunos hallazgos cuya fragmentación, no permite hacer grandes reflexiones a este fenómeno. Entre ellos destacamos una letra [.]A[.] sobre una composición de motivos verticales culminados por línea perlada procedente de Pamplona (Mezquíriz, 1961: lám. 7, n. ${ }^{\circ}$ 
4). También se localiza otro ejemplar de difícil adscripción procedente de Tricio del que se propone una doble lectura NV o NA(retro) (Mayet, 1984: pl. CCXXI, n. ${ }^{\circ}$ 755). Una $\mathrm{P}$ sobre forma decorada con composición metopada procedente de Ilici (Montesinos, 1991: . $^{\circ}$ $10)$.

En relación a las piezas que presentan plasmaciones irregulares que no permiten completar la lectura encontramos una forma Hisp. 37 de Corella. Ésta cuenta con decoración metopada en el que, en medio de los sepadores ondulados, aparece una figura de una anátrida. De manera paralela a los separadores aparece un cartucho bífido vertical en la que se lee IIX IOF (Mezquíriz, 1961: lám. 7, n. ${ }^{\circ}$ 9).

Para finalizar con las producciones altoimperiales advertir también la presencia de un punzón sobre forma Hisp. 30 con posibles caracteres ibéricos (Mayet, 1984: pl. CXLIII, n. ${ }^{\circ}$ 479; Sáenz Preciado, 1997: 555-556, lám. 91, n. ${ }^{\circ} 603 ; 2018: 296$, n. $^{\circ} 39$ ) que, como ya se ha apuntado, podría ser un ejemplo clave para entender la inserción del figlinario local en la producción hispana.

Este fenómeno parece quedar silenciado en el siglo III d. C. y habrá que esperar hasta fines del IV d. C. para volver a apreciar este fenómeno del sellado externo, mayoritariamente a partir de epígrafes en relieve con algunos casos de texto retro (Paz Peralta, 2013: 504 y fig. 19).

\section{LA PRESENCIA DE SIGILLA DECORATIVOS EN LA PROVINCIA LVSITANIA}

A continuación, iremos analizando las piezas que hemos localizado en la provincia Lusitania a raíz del proyecto al que, anteriormente, hemos hecho alusión. Los datos específicos contextuales de cada una de las piezas se pueden seguir bien en la tabla sinóptica (Fig. 13) o bien al hilo de la narración.

La ordenación se hará a partir de grupos organizados por alfareros a los cuáles los asociamos. Este elenco se formaliza alfabéticamente quedando un último subgrupo para aquellas piezas que, desgraciadamente, no podemos asociar a ningún alfarero.

\subsection{LAPILLVS}

El primero de los alfareros localizados en este repertorio sería Lapillus (Fig. 2). Asociamos a este artesano 10 de los ejemplares tratados en esta muestra hecho que supone el $17 \%$ del total. A priori, podemos decir que este artesano se define como uno de los alfareros más versátiles en lo que se refiere al tipo de firma usada en registro externo. Utiliza tanto punzones con cartuchos rectangulares, caracteres a mano alzada, así como inscripciones integradas en el repertorio decorativo.

A día de hoy no hay duda sobre su procedencia riojana, pero con clara antroponimia de origen céltico (Mayet, 1984). Sin embargo, su abrumadora presencia en suelo lusitano hizo a algunos autores plantear la posible existencia de sucursales en la zona. En esta línea, Mayet (1970) inició un interesante debate a propósito del elevado volumen de piezas halladas en Mérida. Esta reflexión, planteada de manera paralela a la figura de Valerius Paternus, concluyó en el momento en el que se desarrollaron análisis arqueométricos que apuntaban a los centros productores de La Rioja como focos de producción (Mayet, 1984; o de manera más reciente Buxeda y Madrid, 2013: tab. 1). La acertada reflexión planteaba, como respuesta a este fenómeno de acumulación de marcas en un espacio geográfico concreto, una estrategia de «marketing» pensada y madurada por parte de los negotiatores que comercializaron los productos de este alfarero en el hinterland de la vía de la plata (Mayet, 1984: fig. 14). Esta práctica de tomar como referencia algunas ciudades que actúen como centros redistribuidores, no es algo exclusivo de esta categoría cerámica, que pudo tomar a Augusta Emerita como núcleo distribuidor, sino que es una práctica que afectó a otras producciones sinterizadas que terminaron basando su éxito en estas pensadas redes de distribución (van Oyen, 2015: 293).

La procedencia de los 10 sellos que ahora presentamos se reduce a: 8 de Mérida; 1 de la villa de El Saucedo y 1 de Conimbriga. Todos los ejemplares procedentes de Mérida fueron localizados en una excavación de reciente desarrollo. El estudio estratigráfico de las piezas permitió definir la vida funcional de este alfarero entre fines del I d. C. y la segunda mitad del II d. C. (Bustamante-Álvarez, 2013) -Fig. 2: n. ${ }^{\circ}$ 1-3, 5-6 y 8-10-. El otro ejemplar con contexto conocido, el de El Saucedo, nos habla de un fuerte componente de residualidad al aparecer en un estrato datado a fines del III d. C. (Fig. 2: 7) que claramente aparece como tránsito hacia las marcas que se extenderán en la producción tardía (Paz Peralta, 2008: 504).

En relación a los grupos decorativos en los que podemos agrupar las piezas selladas asociadas a este alfarero se resumen en composición corrida y metopada.

En relación a la primera se atisban tres sistemas: los círculos concéntricos triples (Fig. 2: 1-4), las inscripciones decorativas (Fig. 2: 7) así como los motivos circulares que enmarcan otros elementos (Fig. 2: 6). Centrándonos en los círculos concéntricos triples, aparecen en doble registro. La composición, hasta en tres ocasiones, se repite. El círculo más externo es sogueado mientras que los internos son lisos. La separación entre ambos frisos decorativos se determina, bien por un baquetón liso o bien por uno doble. En relación a los que recurren como separador a un único baquetón liso, utilizan sigillum con cartucho rectangular. Estos sellos se localizan de manera premeditada en la parte superior del registro decorativo inferior paralelo al baquetón liso (Fig. 2: 1-2) o bien de manera perpendicular (Fig. 2: $3)$. En este caso, da la sensación que la lectura de estos sellos no es retrógrada, sin embargo, este dato no se puede asegurar ya que la propia grafía de su nombre, con varias letras con vástagos verticales (-ILLI), puede 


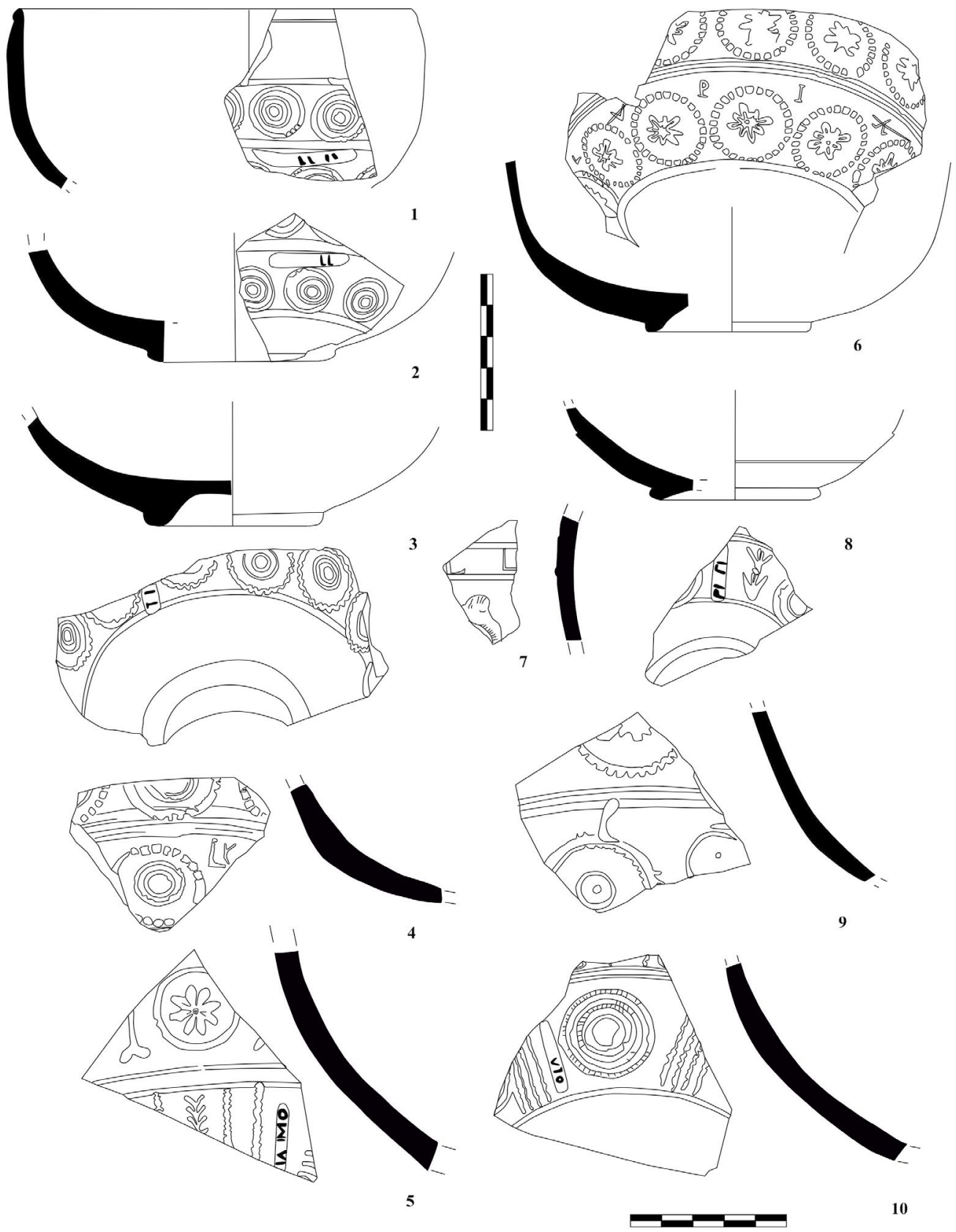

Figura 2: Piezas con marcas alusivas a Lapillus

inducir a error si no está bien impreso. Del análisis contextual de este tipo extrapolamos que nos encontramos en un arco cronológico ubicado entre el 80-90 d. C.

En cuanto al segundo tipo, en el que la separación se hace a partir de doble baquetón, se percibe cómo las letras están hechas a mano alzada sobre el molde, un recurso que también se usará en otras composiciones datadas a inicios del II d. C. (Fig. 2: 4 y 9).

Dentro del grupo de composición corrida, además del motivo al que anteriormente hemos hecho alusión -circulo concéntrico sogueado-, se localiza otro que pudo ser un emblema de este alfarero. En concreto, nos referimos a una flor octapétala en círculo sogueado (Fig. 2: 6 o 9). Los dos ejemplos localizados con esta flor se enmarcan en la primera mitad del II d. C. y en ambos casos se aprecia la presencia de un baquetón doble central.

Pasando a los ejemplares que tienen composición metopada, se pueden articular dos grupos en función de la naturaleza del separador. El primero subgrupo, estaría delimitado por separadores fitomorfos dobles verticales que aparecen flanqueados por dobles círculos concéntricos de los cuales el más externo es sogueado (Fig. 2: 8). Esta composición se repetiría en ambos registros, superior e inferior, separados por baquetón doble. En el ejemplar localizado se percibe cómo el sello en cartucho rectangular se posiciona verticalmente de manera paralela al bastón floral doble. Además de 


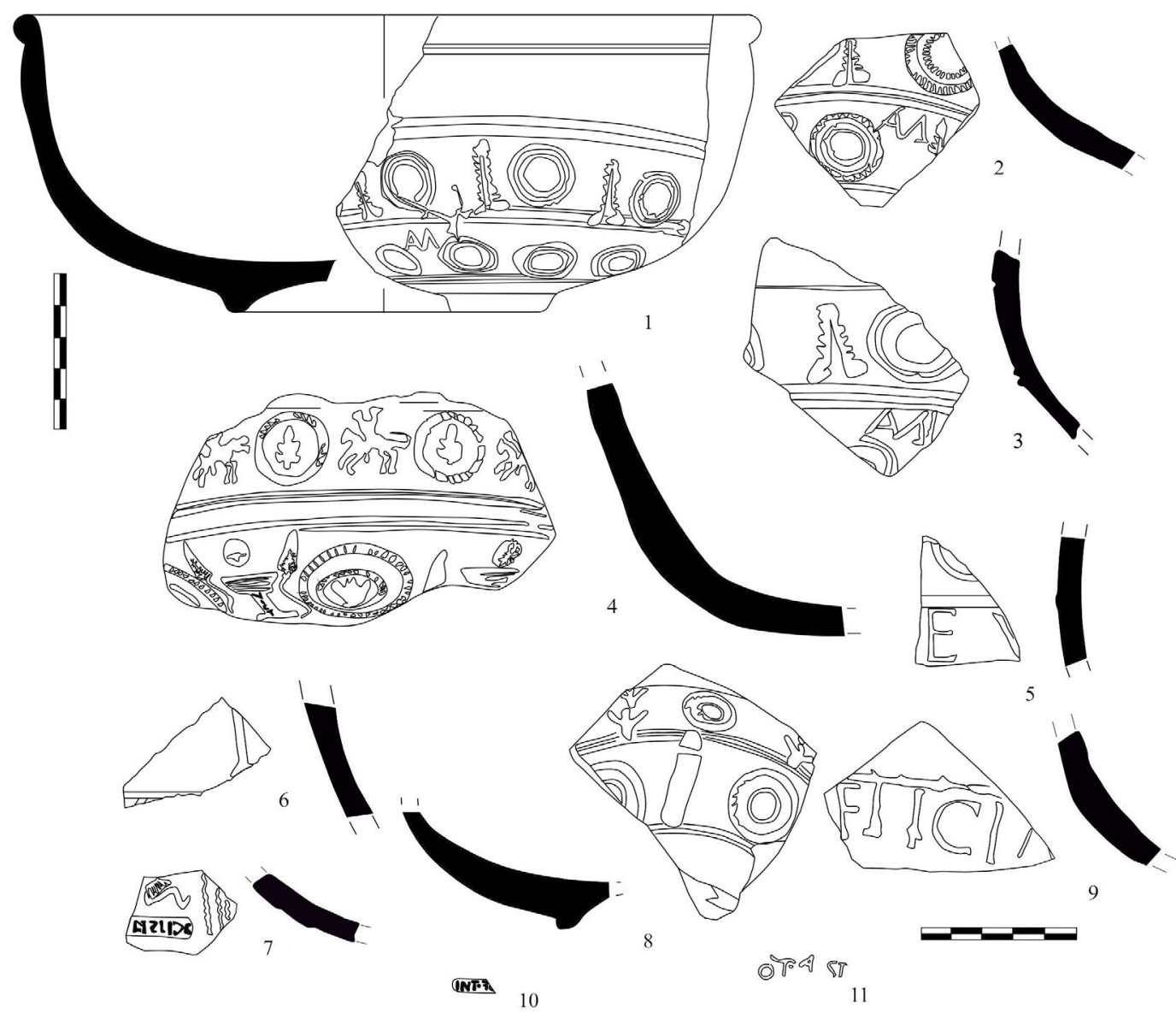

Figura 3: Marcas de alfareros variados, así como piezas con lecturas ilegibles (dibujos de la autora, a excepción de los n. 2-3 y 10-11 realizados a partir de Mayet, 1970: pl. 2, n. 5; Jerez Linde, 1996: n. 119; Mayet 1984, pl. CCXIX y Mezquíriz, 1961: lám. 7, n. 8 respectivamente)

esta pieza, donde se lee el nombre del alfarero, hay otro ejemplar en el que la grafía no ha quedado bien plasmada y que hemos incluido en el grupo de ignotos (Fig. 3: 8) pero que, por composición y ubicación, podríamos estar ante un ejemplar salido del mismo molde. Estos dos ejemplares -legible e ilegible-localizados se ubican en la segunda mitad del II d. C. y nos permite determinar una producción tardía en el tiempo.

El segundo subgrupo de separadores sería el de los bastones verticales quebrados aunados en grupos de dos, tres y hasta cuatro (Fig. 2: 5 y 10). En todas las piezas localizadas se usa el sigillum en cartucho cuadrangular tanto en vertical como en horizontal. La combinación se puede dar junto con líneas bifoliaceas, festones fitomorfos (Fig. 2: 5) o círculos concéntricos cuádruples sogueados (Fig. 2: 10). Sólo hay un ejemplar que presenta un motivo que anteriormente hemos visto asociado a la composición corrida. Nos referimos a la flor octapétala (Fig. 2: 5). Las piezas con decoración de festones ondulados se pueden datar estratigráficamente en la mitad del II d. C.

En relación a las inscripciones decorativas tenemos un único ejemplar (Fig. 2: 7) inserto en el friso superior, en el que se lee [.]LL[.] y se acompaña con una posible representación fitomorfa en el registro inferior.
Es evidente que este ejemplar, lo mismo que ocurre con las letras sueltas, es preciso confirmarlo cuando se produzcan hallazgos más completos. El único con inscripción decorativa procede de la villa del Saucedo, concretamente de los paquetes preparatorios para la construcción del balneum datado a fines del III d. C. $\mathrm{y}$ vinculables a tierras de acarreo, lo que le añade una fuerte carga de residualidad.

De todos los motivos analizados observamos cómo hay dos que se podrían haber convertido en distintivo de este alfarero, al menos, por un tiempo transitorio como es la flor octopétala así como el elemento vertical doble. El otro motivo reiterado, el círculo concéntrico sogueado y liso, aunque fue recurrente en su producción, creemos que también fue usado de manera indistinta por otros alfareros.

En relación al formulario epigráfico usado se puede dividir en los siguientes: OF(FICINA) u O(FFICINA) LAPILLI, LAPILLI o bien LAPILA. En cuanto a los recursos epigráficos el único que se ha observado es la presencia de una A invertida en uno de los ejemplares (Fig. 2: 6) hecha a mano alzada sobre el molde fresco. En el mismo ejemplar se advierte además una $\mathrm{A}$ con el trazo horizontal muy prolongado que podría haber sido la plasmación de una ligadura. 


\section{2. $\operatorname{MAS}($.}

La definición de un posible alfarero de nombre $\operatorname{Mas}($. vino de la mano de Mayet (1984: 150, n. ${ }^{\circ} 352$ ) al analizar uno de los ejemplares que traemos a colación. Esto nos plantea una serie de problemas añadidos al no tener datos exactos de procedencia que ayuden a definir cronológicamente la producción (Fig. 3: 1-3).

De este alfarero se han localizado tres ejemplares de sellos (5,3\% de la muestra) sobre forma Hisp. 37 con doble registro decorativo, separado por baquetón doble (Fig. 3: 1-3). Concretamente, en la parte superior aparecen círculos concéntricos dobles que, inicialmente fueron sogueados, pero que con el sobreuso del molde pudieron borrarse dichos aderezos. Estos círculo están separados por un separador fitomorfo lanzeolado hueco. Por el contrario, en la zona inferior puede aparecer tanto composición corrida de círculos concéntricos (Fig. 3: 1) como pseudometopada con separadores verticales (Fig. 3: 2).

En cuanto al sello aparece en las tres ocasiones a mano alzada en el registro inferior, retrógrado y con una ligadura epigráfica en la que leemos $\underline{\mathrm{MA}}$. En una ocasión se le asocia la letra S (Fig. 3: 2). De ninguno de los dos ejemplares tenemos datos sobre su contexto de aparición lo que nos dificulta cualquier tipo de adscripción cronológica.
En este caso, se observa cómo el separador fitomorfo al que hemos hecho alusión, claramente, podría ser un emblema del taller en cuestión ya que es infrecuente en la producción hispana.

Nos parece de interés la reiteración de este motivo en una pieza que presenta un doble sellado enfrentado, por un lado, VAP y por otro MAS (retro) que comentaremos más adelante y que nos permite plantear una posible actividad asociativa entre ambos alfareros (será analizado más adelante en la Fig. 5: 11). Sin lugar a dudas, son pocas las evidencias que tenemos para definir si hubo o no una relación jerárquica de dichos alfareros, pero la masiva producción de Valerius Paternus nos permite definir un posible fagocitado por su parte de la manufactura de Mas como abordaremos líneas más adelante.

\subsection{SEMPRONIVS}

Un 16\% de la muestra, esto es 9 piezas, corresponde al alfarero Sempronius (Fig. 4). Todos estos ejemplares proceden de la antigua capital de la Lusitania, un lugar muy prolífico para sus negocios como se deja patente en otros estudios de similar calibre (Bustamante-Álvarez, 2013).

Sempronius es uno de los únicos alfareros que comercializó más allá de la frontera hispana. Concretamente,

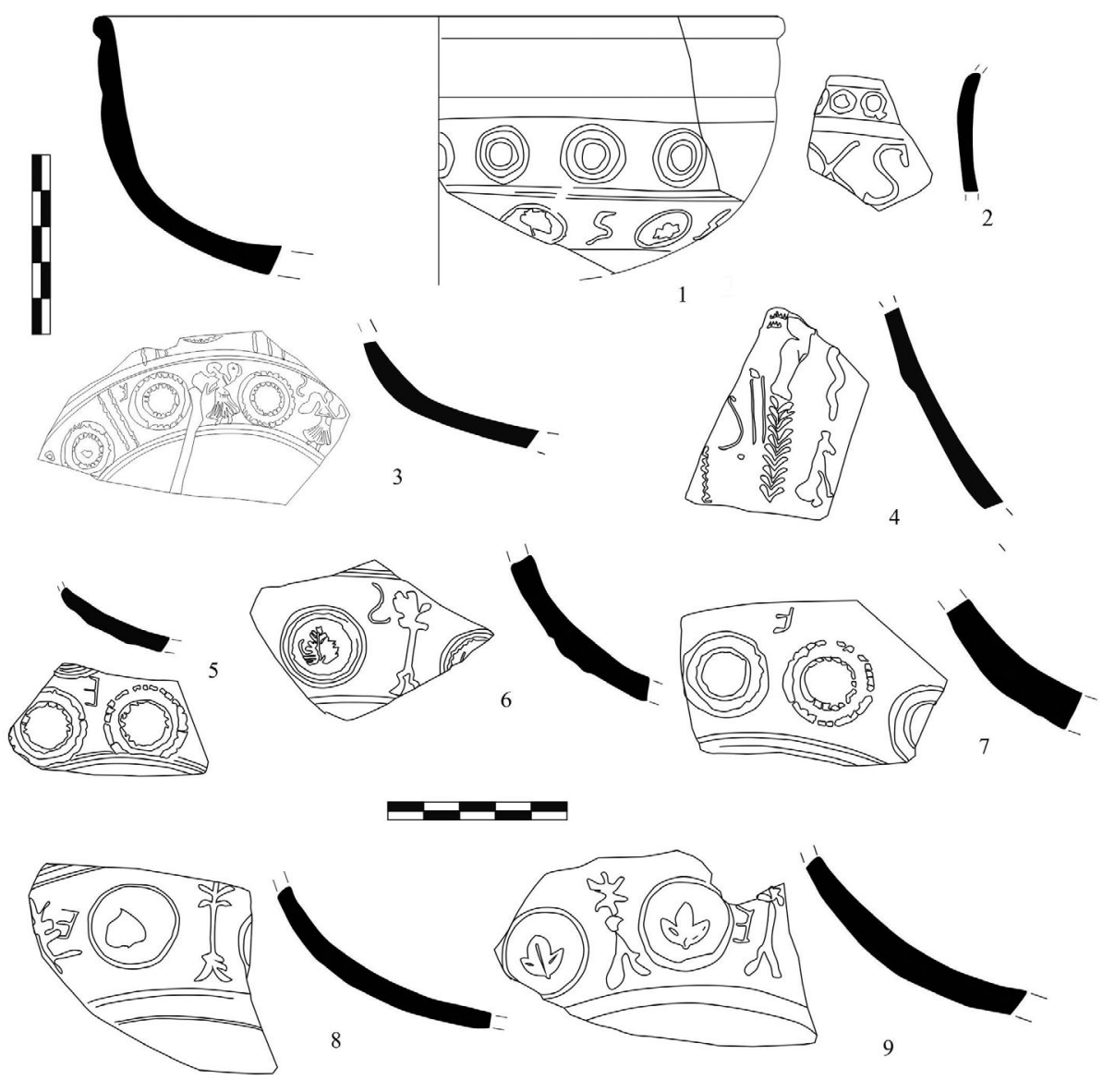

Figura 4: Ejemplares con sellos asociables al alfarero Sempronius 
hay un ejemplar en Londres o Colonia (Garabito, 1978) algo que parece que fue un fenómeno puntual en la producción hispana a excepción de la comercialización con el norte de la Mauritania Tingitana. Sin embargo, en el caso concreto de este alfarero es importante apuntar que no siempre ha habido unidad en la interpretación de que estas piezas fuera de Hispania, ya que el nomen Sempronius no fue exclusivo de la producción regional pudiéndose haber dado una confusión a este respecto (Romero, 1985: 277).

De los ejemplos que ahora presentamos, a excepción de uno que procede de un contexto de exhumación relativamente reciente, la c/ Hernán Cortés, los restantes forman parte de los depósitos antiguos del MNAR. El único ejemplar en contexto, localizado en un depósito cerrado - puticuli - ofrece una cronología de fines del I d. C.

Todas las piezas tipológicamente se pueden adscribir a la forma Hisp. 37 y, estilísticamente, se perciben cuatro grupos compositivos. En ningún caso, se observa la presencia de sigilla en cartucho rectangular sino se alternan tanto marcas hechas a mano alzada, en el molde sin conexión con la composición o bien epígrafes que pudieron haber sido hechos con punzones con letras y en conexión con el discurso decorativo.

El primero de los grupos compositivos se asocia al estilo decorativo continuo de dobles círculos concéntricos sogueados, distribuidos en dos registros que pueden estar o no separados ambos frisos por doble baquetón liso (Fig. 4: 1 y 5). Dentro de esta composición continua, se advierten dos variantes. La primera de ellas corresponde a una composición corrida en dos registros separados por doble baquetón liso (Fig. 4: 1). En el registro superior aparecen círculos concéntricos dobles sogueados. En el registro inferior, el círculo sogueado enmarca flores multipétalas y, actuando como separadores, aparece una $\mathrm{S}$ que se repite de manera equidistante. La segunda es una composición continua con círculos concéntricos dobles sogueados en dos registro sin separación entre ellos. Entre los círculos se han localizado una $\mathrm{E}$ retrógrada de perfil muy fino y respetando la composición (Fig. 4: 5 y 7). Posiblemente, en toda esta composición se desarrollase el nombre del alfarero siendo preciso girar el vaso $180^{\circ}$.

El segundo grupo estilístico corresponde a una composición pseudo-metopada de la que únicamente contamos con el registro inferior. Se alternan círculos concéntricos dobles con festones verticales fitomorfos (Fig. 4: 6, 8 y 9). Los círculos son dobles, el exterior es simple y el central sogueado. Este motivo circular enmarca una trifolia con los nervios bien indicados. El elemento vertical presenta un acabado en tridente y el pie bífido. Se ha localizado, hasta el momento, ejemplares con $\mathrm{S}$ y $\mathrm{E}$ ambas letras retrógradas que nos inducen a pensar que el nombre se completaría por todo vaso.

El tercer grupo corresponde a una composición metopada a partir de festones verticales bifoliáceos culminados por un posible erote desnudo (Fig. 4: 4). Únicamente, contamos con el registro inferior. Además se advierte una línea vertical ondulada así como un pequeño cánido. Entre la línea bifoliacea y la ondulada aparece una letra S e II retrógrada. En este caso interpretamos II como una $\mathrm{E}$ arcaica siendo, por consiguiente, la posible lectura SE(MPRONIVS). Como ya analizamos al abordar el elenco de alfareros, hay un ejemplar procedente de Arcobriga que guarda grandes similitudes con esta pieza. Concretamente, nos referimos a una forma Hisp. 37 con decoración también metopada y con epigrafía similar a esta pieza (Juan Tovar, 1992: 74, n. ${ }^{\circ} 13$ y fig. 1.3.25, n. $\left.{ }^{\circ} 234\right)$. Sin embargo, en este caso se apuntó directamente a Segius Tritiensis, interpretación que tampoco podemos considerar como incorrecta pero que habrá que reconsiderar en futuro próximo si se localizan ejemplares más completos.

El cuarto grupo corresponde a una composición más compleja conformada por una línea de perlas sobre baquetón que delimitan superiormente la inscripción [E]XS[EMPRONIVS] (Fig. 4: 2). En este caso las letras no aparecen retrógradas. Este hecho, unido a que aparece en el registro superior, claramente, nos habla de un interés directo para que el consumidor lea dicho mensaje.

De todos los motivos que se incluyen dentro de estas piezas decoradas asociadas a Sempronius, la trifolia así como el elemento vertical culminado con tridente, podrían ser símbolos claramente asociados a la producción de este alfarero, al menos, en sus momentos iniciales de su vida activa.

En relación a los recursos epigráficos simplemente hacer hincapié en el desarrollo de las letras a mano alzada -a excepción del punzón S- sin tener presente su carácter retrógrado que adquieren en el momento que pasan a la pieza en positivo. Esto, quizás, apunta a una posible falta de interés en el que el usuario fuese capaz de leerlo lo que induce a pensar que sea una marca interna del alfar ya que, al no depender de ningún punzón, se podría haber subsanado fácilmente este problema de plasmación retro.

\subsection{VALERIVS PATERNVS}

Del alfarero Valerius Paternus hemos localizados 26 ejemplares (46,26\%), una muestra lo significativamente numerosa para calibrar el impacto que tuvo la producción de este alfarero en la región a estudiar. De hecho, lo mismo que ocurre con el otro artesano mayoritario, Lapillus, algunos autores han apostado por un posible taller, bien autónomo o bien sucursal en suelo lusitano. En concreto, esta teoría fue lanzada por Mayet (1970) a propósito de un trabajo monográfico sobre el tema donde, recurrentemente, analizaba este fenómeno haciendo especial hincapié en su distribución y apabullante presencia en Mérida como queda patente en algunos mapas cuantitativos planteados por esta autora (Mayet, 1984: 228, fig. 13). Lo mismo que ocurrió con la investigación de Lapillus; los análisis arqueométricos volvieron a poner sobre la mesa su origen norteño 


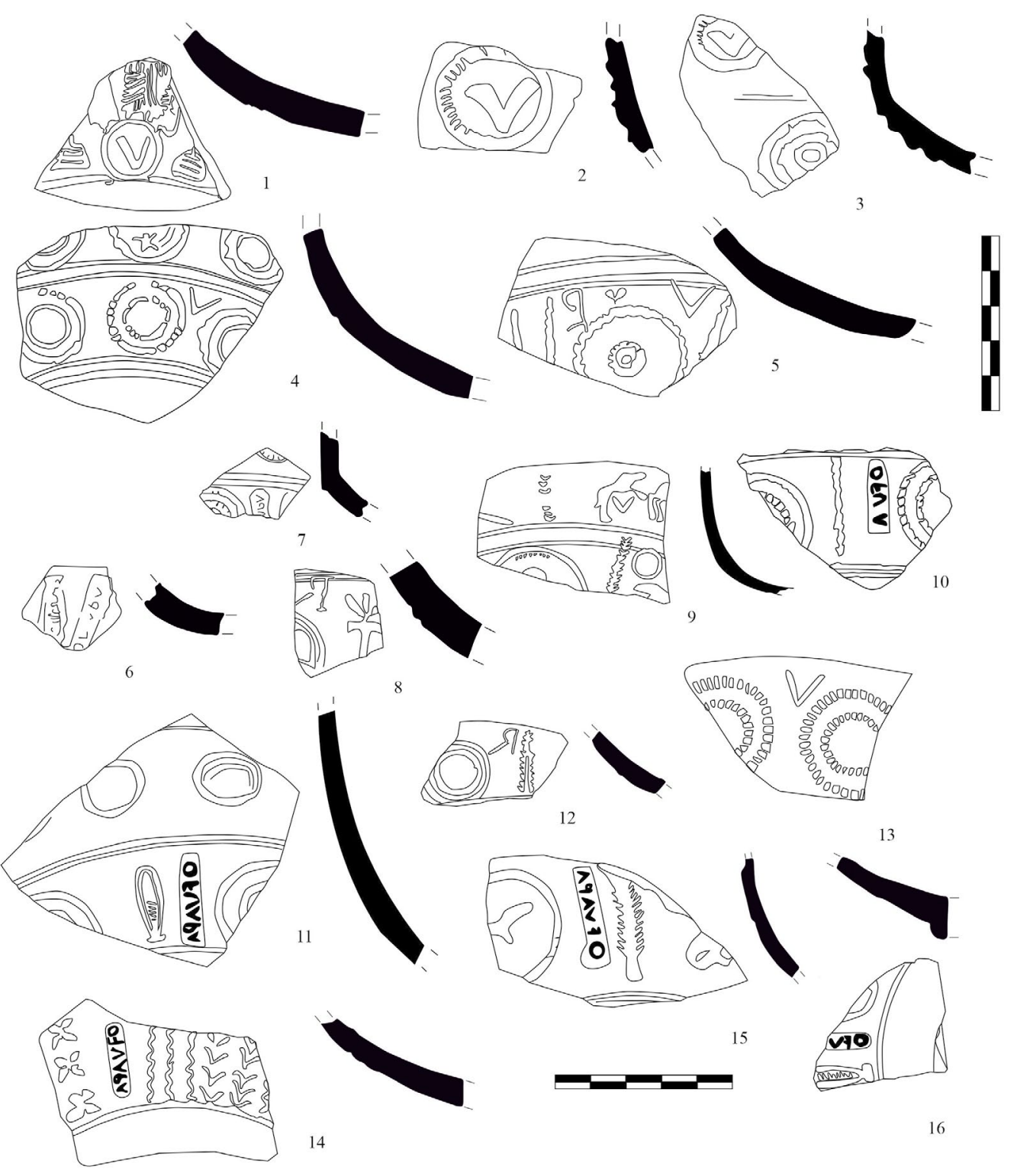

Figura 5: Piezas con sellos que se pueden asociar a Valerius Paternus, parte I (dibujos de la autora, a excepción de los n. 2-3, 6, 7, 13-14 realizados a partir de Jerez Linde, 1996: n. 117-118, 115, 116; Mayet, 1970: pl. 2, n. 6 respectivamente)

(Mayet 1984: 231, nota 30; de manera más reciente Buxeda y Madrid, 2013). Interesante resulta su presencia en contextos extrapeninsulares, concretamente en Stokstadt -Alemania- (Garabito, 1978: 318) que nos habla de una capacidad organizativa extraordinaria. Antroponímicamente, el nombre Paternus se ha incluido dentro de los denominados como deckname, esto es un nombre latino que es una traducción de antropónimos indígenas, en este caso vinculado a relaciones de parentesco (Simón, 2016: 106).

De los 26 ejemplares localizados se han podido aislar las siguientes composiciones: corridas y metopadas. Hasta el momento no se ha localizado ningún ejemplar que presente un friso epigráfico corrido. Mayoritariamente, las piezas proceden de Mérida con un predominio de los contextos de vertedero y, además, de los fondos antiguos del MNAR que generan problemas de fiabilidad de su procedencia. La decena de piezas contextualizadas nos permite definir que su arco cronológico se centra en la primera mitad del II d. C.

En relación a las firmas que hemos documentado se localizan tanto marcas en cartucho rectangular como letras sueltas. Lo mismo que ya hemos planteado con otros alfareros, para poder comprender en plenitud dichas letras tendremos que esperar a encontrar piezas completas para hacer algunas precisiones sobre su desarrollo. Sin embargo, la reiteración de determinados motivos ornamentales, así como la presencia repetida de este alfarero en suelo luso es clave para hacer este tipo de puntualizaciones.

Una de las composiciones dominantes por parte de este alfarero fue la corrida por medio de la reiteración de motivos similares. La composición más 

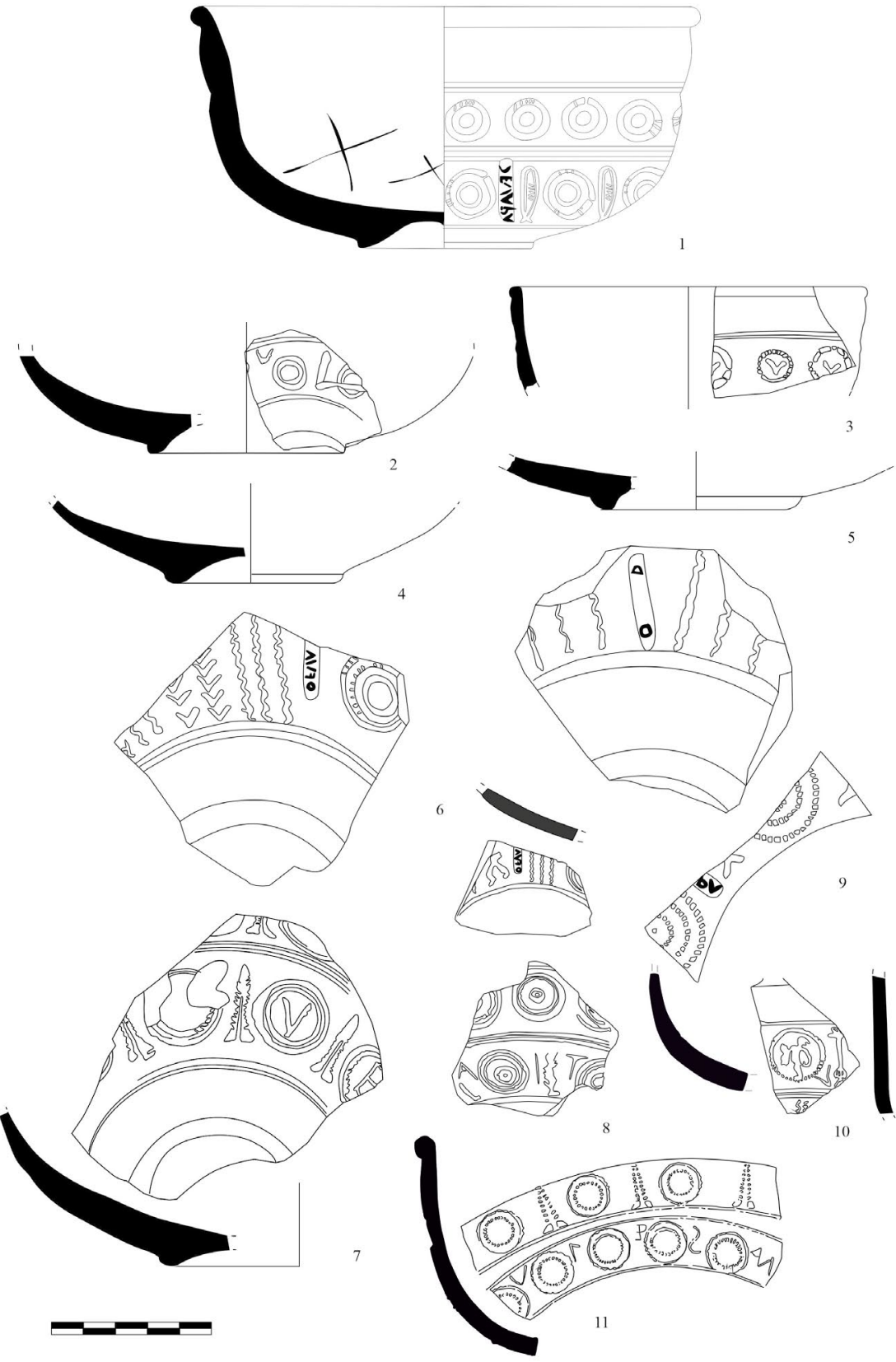

Figura 6: Piezas con sellos que se pueden asociar a Valerius Paternus, parte II (dibujos de la autora, a excepción de los n. 1, 6, 9 y 11 a partir de Mayet, 1970: pl. 1, n. 1; Mayet, 1970: pl. 2, n. 4; Mayet, 1970: pl. 1, n. 3; Mezquíriz, 1960: lám. 7, n. 5)

simple vendría de la mano de círculos concéntricos lisos (Fig. 5: 4 y Fig. 6: 2) o bien sogueados (Fig. 5: 13). En todos los casos se observa cómo el sello aparece sin cartucho y dibujado a mano alzada sobre el molde. Únicamente tenemos referenciado una $\mathrm{V}$ que aparece entre los huecos de los «intercirculos» del registro inferior, muy pegada al baquetón central. El único ejemplar de este tipo contextualizado nos permite determinar su producción a inicios del II d. C. (Fig. 6: 2). Como una posible subvariante de este grupo se encontrarían aquellos motivos circulares que presentan en el centro una $\mathrm{V}$ hecha a punzón y que aparecen formando parte de la composición corrida (Fig. 5: 2-3 o Fig. 6: 3) o bien inserta en una ordenación más compleja (Fig. 5:
1 o Fig. 6: 7). En el caso de esta letra, sí fue diseñada a partir de punzón, método que ofrece gran homogeneidad al diseño. El único ejemplo localizado en contexto nos indica que estamos ante una pieza comercializada a inicios del II d. C. (Fig. 6: 2).

El siguiente grupo ornamental corresponde a las denominadas como composiciones metopadas. Dentro de este conjunto, sobresale, por su excepcionalidad, los elementos gallonados verticales que se han localizado hasta en cinco ocasiones (Fig. 5: 6-7, 11 y 16 y Fig. 6: 1). En este caso, estas figuras suelen alternar con círculos concéntricos. El único ejemplar en contexto, de nuevo, alude a inicios del II d. C. como datación (Fig. 5: 6). El sigillum, en esta ocasión, se plasma de manera 
vertical usando el mismo punzón que para las piezas lisas. En algunas ocasiones se ubica de arriba hacia abajo y viceversa por lo que no hay homogeneidad en la práctica. El que sea un punzón destinado a piezas lisas y planas genera que el plasmado final no sea el deseado diluyéndose en la composición.

Otros separadores verticales dentro de las composiciones metopadas serían las líneas onduladas (Fig. 5: 5 y 10 y Fig. 6: 5-6) donde mayoritariamente se usa el punzón en cartucho rectangular a excepción de un ejemplar con letras a mano alzada. Los ejemplares con cartucho que han aparecido contextualizados nos aportan una datación centrada a mitad del II d. C. (Fig. 6: 5-6). El otro separador usado por este alfarero serían los bifoliáceos (Fig. 5: 14 y Fig. 6: 4) en los que el sello aparece de manera vertical mimetizándose con la composición en sí. En relación a los festones fitomorfos (Fig. 5: 8, Fig. 5: 7, 9-10) aparecen dos tipos, el primero en que el motivo de separación es un vástago central liso atravesado por pequeños aderezos en los que se observa tanto sellos en cartucho (Fig. 6: 9) como incisos (Fig. 5: 8 y Fig. 6: 10). De estos ejemplares, el único contextualizado nos aporta una cronología de mitad del II d. C. (Fig. 6: 10). El segundo elemento de separación es un vástago en el que aparecen ramas con interior macizo (Fig. 5: 15 y Fig. 6: 8) o hueco (Fig. 5: 12 y Fig. 6: 7) donde, de nuevo, el abanico de posibilidades de marcación es amplio desde sellos incisos, con cartuchos rectangulares hasta letras insertas en elementos circulares. De nuevo, el único ejemplar contextualizado se ubica a mitad del II d. C. (Fig. 5: 15).

Para finalizar con el prolífico repertorio de este alfarero, destacar la presencia de composiciones compuestas con figuraciones de difícil interpretación por el grado de obliteración. La primera corresponde a un fragmento con un cartucho circular V sobre la que aparece una figura togada. En este caso la letra se plasma a punzón (Fig. 5: 1). Esta pieza, no descartamos que pudiera pertenecer al alfarero Victor-que tratamos a continuación-, atendiendo a su composición con cartelas circulares, la figura con toga, así como la posible presencia de varas florales que, debido a su estado de fragmentación, no podemos analizar de manera más extensa (Sáenz Preciado, 1994: lám. 37). La segunda pieza con composición de difícil interpretación corresponde a una ordenación metopada con figuras zoomorfas en movimiento delimitadas por metopas de líneas bifoliaceas (Fig. 5: 9). Este último se ha fechado a mitad del II d. C. ${ }^{12}$

En relación a las fórmulas epigráficas usadas, los ejemplares con sellos en cartucho utilizan el formulario OF VAPA. La dirección de la inscripción es tanto de arriba-abajo como de abajo-arriba por lo que no hay un planteamiento predeterminado. Interesante resulta el

12. Resulta de interés la presencia de una marca con figuración similar sobre el interior de un molde localizado en Tritium Magallum (Roca y Fernández, 1999: 311). uso de la A sin vástago horizontal algo muy recurrente en la producción de este alfarero.

En relación a las letras sueltas, aparecen tanto $\mathrm{V}$, $\mathrm{R}$ que, por similitud con las otras composiciones, nos puede aportar algunas pistas de adscripción. También aparece una V y LP (ligadas) que ya se apuntó inicialmente que podría corresponder a este alfarero (Comfort, 1961: 10, fig. 10). Sin embargo, en publicaciones posteriores se han priorizado como lectura $\mathrm{V}$ y PL (Mezquíriz, 1985: 142, n. 326; Sáenz y Saénz, 1999: 134).

\subsection{VICTOR?}

La pieza que pasamos ahora a analizar corresponde a una forma híbrida 29/37 (Fig. 3: 4). Presenta un discurso decorativo complejo dividido en dos registros. El superior aparece conformado por círculos sogueados con hoja caduca en el centro que altera con jinetes en movimiento. En el registro inferior, separado por dos baquetones dobles, aparece un doble círculo concéntrico sogueado que enmarca un elemento floral, posiblemente una hoja. Esta cartela se flanquea con ramas fitomorfas culminadas por una hoja y que terminan enmarcando un altar esquemático que en su centro presenta escrito VICT. Este altar parece repetirse a lo largo de toda la pieza pero desconocemos si se duplicaría esta inscripción.

En este caso, la inscripción se enmarca de manera vertical con lectura de arriba a abajo y claramente hecha a mano alzada. Su posicionamiento en el registro inferior de una pieza tan carenada hace que quede fuera de la vista del consumidor.

Al proceder de un contexto cerrado, los puticuli de Mérida podemos concluir una datación fiable de fines del I d. C.

Una vez plantada la descriptiva de esta pieza nos surge la siguiente duda de si realmente estamos ante un alfarero o si, simplemente, nos referimos a una inscripción apotropaica vinculada al altar en cuestión.

Interesante resulta el paralelo localizado en $\mathrm{La}$ Cereceda (Arenaza de Arriba) donde, de nuevo, aparece el altar con la marca VICT en su estipe (Sáenz Preciado, 1994: 96, n. ${ }^{\circ}$ 37). En este caso la C aparece retro pudiendo ser un símbolo característico de este taller. La composición en este caso es ligeramente distinta a la que aquí presentamos. Concretamente, el altar aparece flanqueado por dos separadores verticales fitomorfos y se culmina por una cartela circular en la que se representa una crátera, así como un togado que, Sáenz Preciado plantea también como posibilidad que fuera una Victoria.

\subsection{VALERIVS PATERNVS + MAS(.)}

Destaca dentro de la muestra un ejemplar antiguo presentado por Mezquíriz (1961: lám. 290, n. 56) 
procedente del MNAR y que, desgraciadamente, no se localiza actualmente en sus depósitos (Fig. 6: 11). Concretamente, es un fragmento de Hisp. 37 con doble registro decorativo. El superior formado por círculos concéntricos sogueados que alternan con separadores verticales fitomorfos huecos. El inferior, por el contrario, usa elementos verticales, sin embargo, deja de lado los separadores. En su lugar y separando cada uno de los círculos se ubican letras incisas que nos permiten leer una curiosa combinación de dos nombres. El primero escrito de izquierda a derecha en el que se puede leer VAP y que asociamos a Valerius Paternus $\mathrm{y}$, el segundo, de manera retro en el aparece recogido MAS que podría asociarse con el alfarero Mas(.). Sin lugar a dudas, el cambio de dirección es intencional y claramente nos hablaría del asociacionismo de ambos alfareros en esta empresa comercial. A ello hay que unirle que hay motivos, como el bastón floral hueco, que aparece en la producción de ambos artesanos y que nos hablaría de la transferencia de determinados motivos bidireccionalmente.

\subsection{EJEMPLARES ILEGIBLES Y DE DIFÍCIL ATRIBUCIÓN}

Dentro de este grupo insertamos algunas piezas que bien por su fragmentación, bien por débil impresión o bien por plantear problemas de lectura no podemos asociar a alfareros concretos del elenco hasta el momento definidos.

- sello ilegible (Fig. 3: 8) este ejemplar localizado en un contexto datado a mitad del II d. C. presenta una decoración dividida en doble registro. En el friso superior aparecen círculos concéntricos sogueados y simples con separadores dobles verticales fitomorfos. En la parte inferior y de manera vertical aparece un cartucho rectangular con sello ilegible debido a que no se quedaron marcadas las letras. Aunque lo incluimos en este apartado planteamos la posibilidad de que fuera una pieza manufacturada por Lapillus por el parecido que presenta con una composición a la que anteriormente hemos hecho alusión (Fig. 2: 8).

- letras sueltas ocupando un friso corrido (Fig. 3: 5-6 y 9). Concretamente, se observa una [.]I [.]; así como [.]EV[.] procedentes ambos ejemplares de la villa de El Saucedo y datados a fines del III d. C. El siguiente ejemplar procede de los fondos del MNAR y se puede leer [.]FIICIT[.] que asociamos a la tercera persona del singular del verbo facere. La presencia de estas letras no tuvo que estar siempre asociada a marcas de alfareros. Este dato, claramente, se podrá dilucidar en el momento que se localicen ejemplares completos que ayuden a comprender el discurso. En este caso traemos a colación algunas piezas de la producción gala en las que aparecen fórmulas propiciatorias o de saludo caso de Ave, Feliciter, Pone tu... entre otros y que tratan un discurso alejado de la realidad interna de los centros productores (Genin, 2007: 273). Sin lugar a dudas, esta es una línea a explorar en un futuro.

- sello ilegible (Fig. 3, n. ${ }^{\circ}$ 7) procedente de la excavación de ampliación del MNAR y datado a fines del I d. C. Contiene una marca retro en la que se puede leer OCIISIF[.]. La composición plasmada es metopada a partir de líneas onduladas triples verticales con una figura antropomorfa central con gran escorzo. Esta figura con un faldellín presenta claras similitudes con la documentada en las producciones de Bronchales con un arco de dispersión muy concreto en la zona noreste peninsular como demuestran los ejemplares de Valeria, Corduente -Guadalajara- o Ilici (Sánchez Lafuente, 1985: fig. 27, n. $^{\circ} 13$ y fig. 55, n. ${ }^{\circ}$ 9). Podríamos estar ante el primer ejemplar sellado de este enclave turolense.

Las dos siguientes marcas presentan como particularidad haber sido publicadas de antiguo y no contar con ninguna representación gráfica alusiva a su decoración. La primera de ellas corresponde a un sello en cartucho rectangular retro localizado sobre un ejemplar de Hisp. 37 de Represas y que ha sido asociado al alfarero Tanus del que únicamente se conoce este ejemplar (Mayet, 1984: pl. CCXIX). El siguiente sello corresponde a una pieza supuestamente depositada en el MNAR, pero actualmente en paradero desconocido de la que se han propuesto dos lecturas OAST o AST acompañado de la formulación OF (Mezquíriz, 1961: lám. 7, n. ${ }^{\circ}$ 8; Mayet, 1984: pl. CCVIII). En ambos casos el que únicamente haya un solo ejemplar, sin apenas referencias gráficas, nos plantea algunas dudas a la hora de proceder a una reflexión más concreta.

\section{REFLEXIONES SOBRE ESTE FENÓMENO}

Como ya hemos esbozado previamente el número de piezas que hemos recopilado en suelo lusitano asciende a 56 de las que 25 hasta el momento permanecían inéditas (Figs. 7-12). Esta muestra creemos que es lo significativamente interesante para llevar a cabo un análisis de tipo cronotipoestilístico de las marcas externas de la producción hispana (Fig. 13). Por procedencia, más del $75 \%$ son de Mérida tanto de excavaciones antiguas depositadas en la actualidad en el MNAR como de excavaciones más modernas (c/ Almendralejos 41, Puticuli de la c/ Hernán Cortés o bien Solar de Ampliación del MNAR). El resto de las piezas se difuminan en el espacio. En primer lugar, tenemos cinco ejemplares procedentes del ager emeritense, concretamente 3 del yacimiento de las Termas de Talavera la Real (Badajoz), 1 del yacimiento del Cabezo de Hornachuelos o 1 del yacimiento de la Orden de Guadajira (Badajoz). Fuera de la órbita emeritense tenemos 1 ejemplar procedente de Pax Iulia, 1 de Conimbriga y 3 de la villa del Saucedo (Talavera 

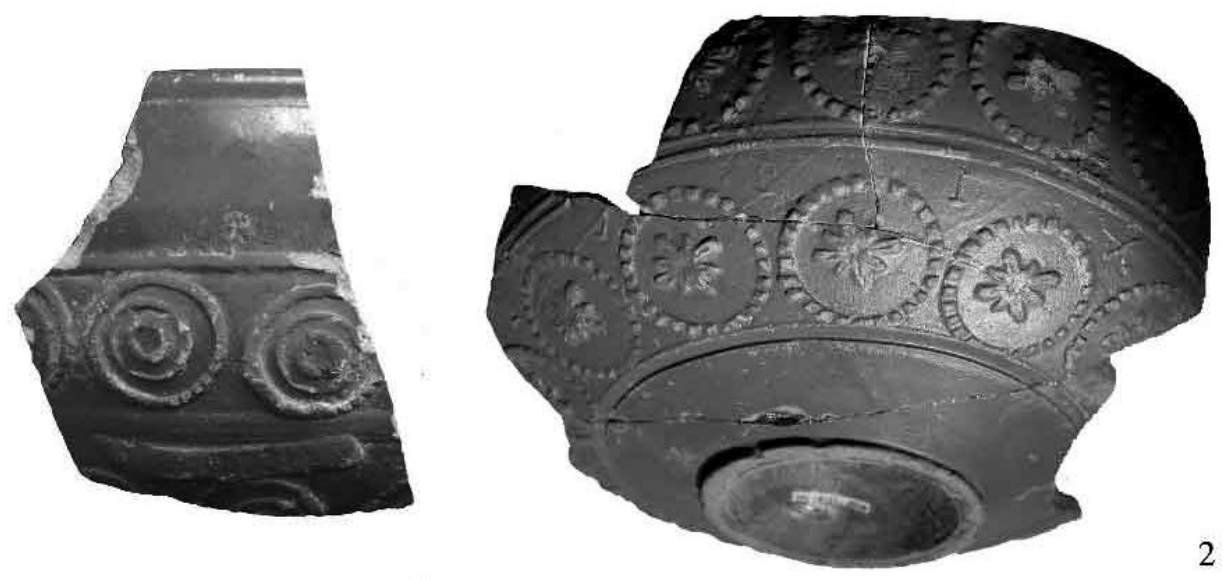

1
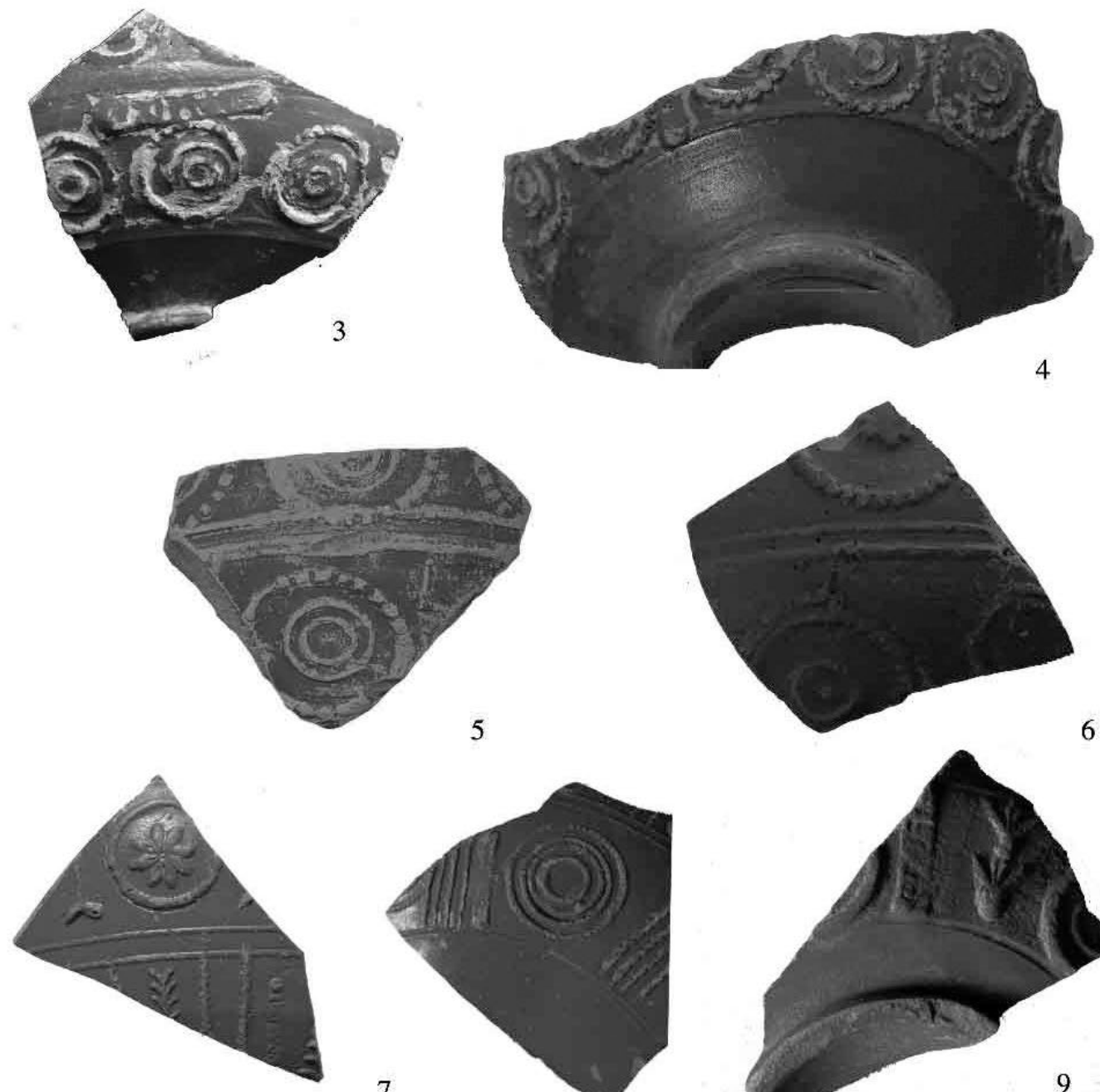

5

7

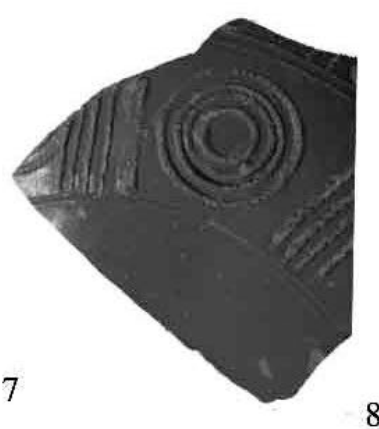

8

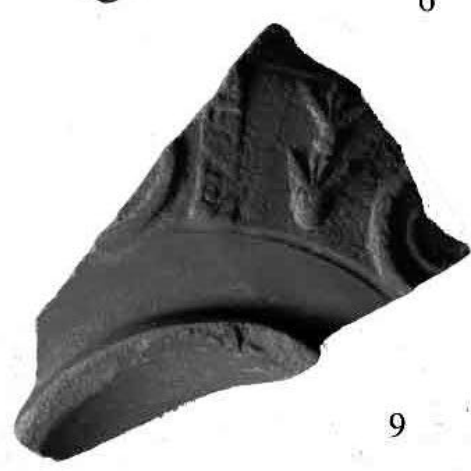

Figura 7: Fotografía de algunas de las piezas asociables a Lapillus

de la Reina, Toledo). De esta dispersión espacial se puede concluir cómo existe una mayor concentración de piezas en el entorno de la vía de la Plata algo que ya ha sido recurrentemente puesto sobre la mesa al analizar las producciones selladas de determinados alfareros. Fuera de este espacio estarían Conimbriga o Pax Iulia cuya entidad podría explicar la llegada, aunque puntual, de estas piezas. 

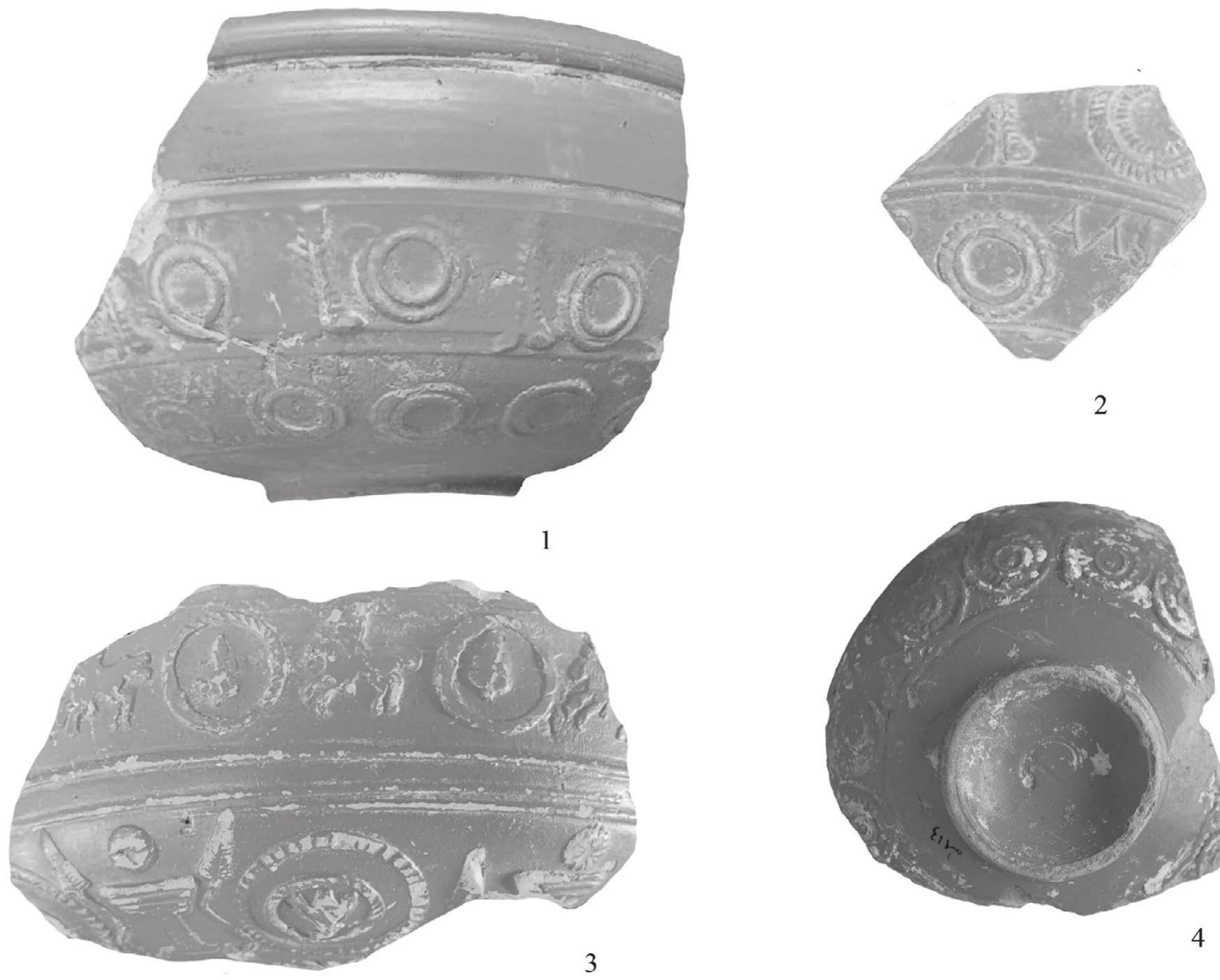

2
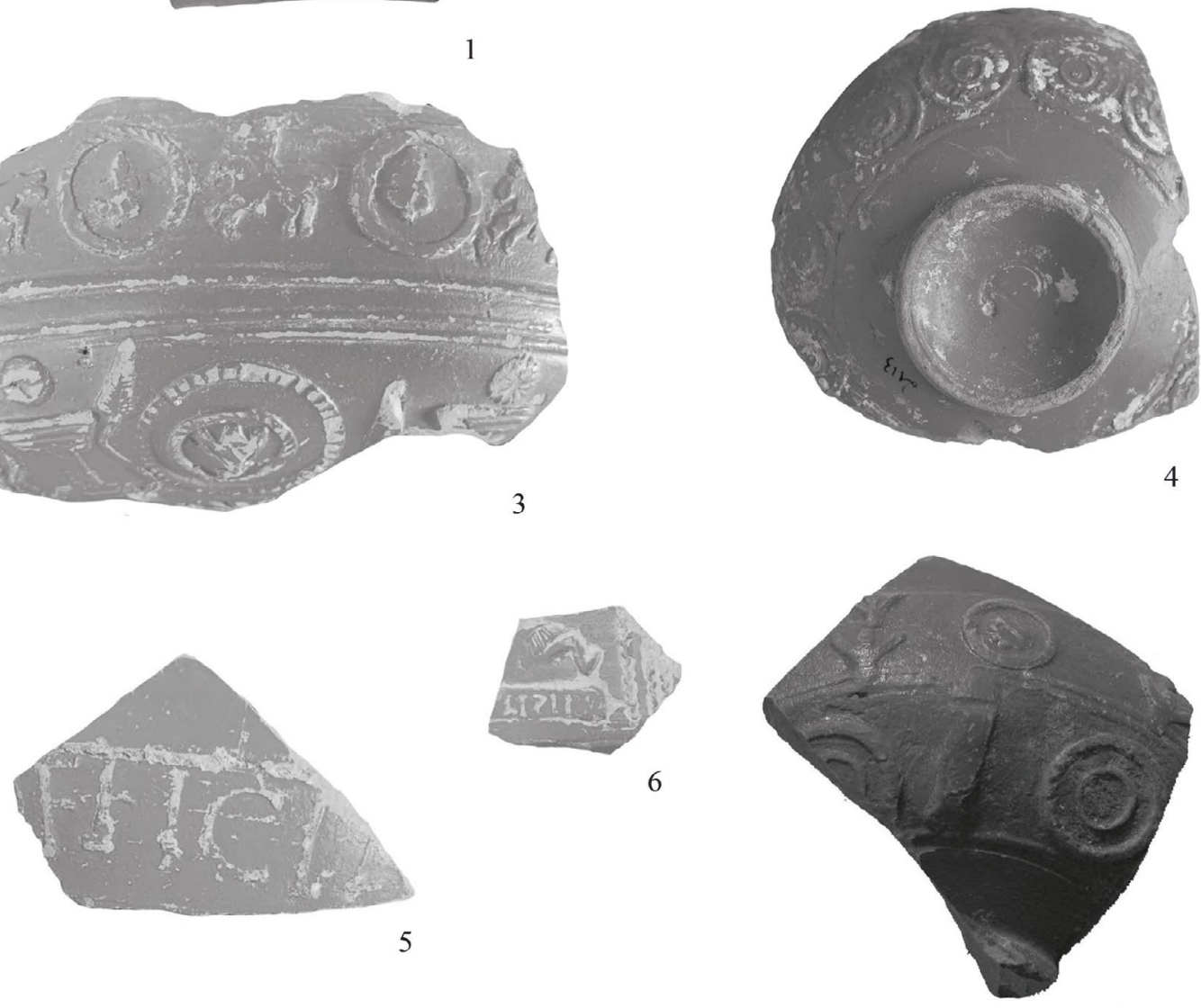

7

Figura 8: Fotografía de algunas de las piezas asociables a otros alfareros 

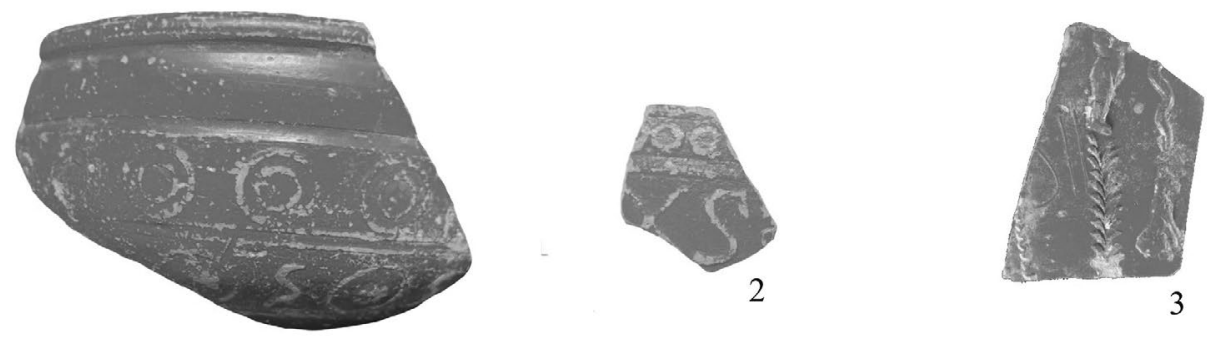

1

3
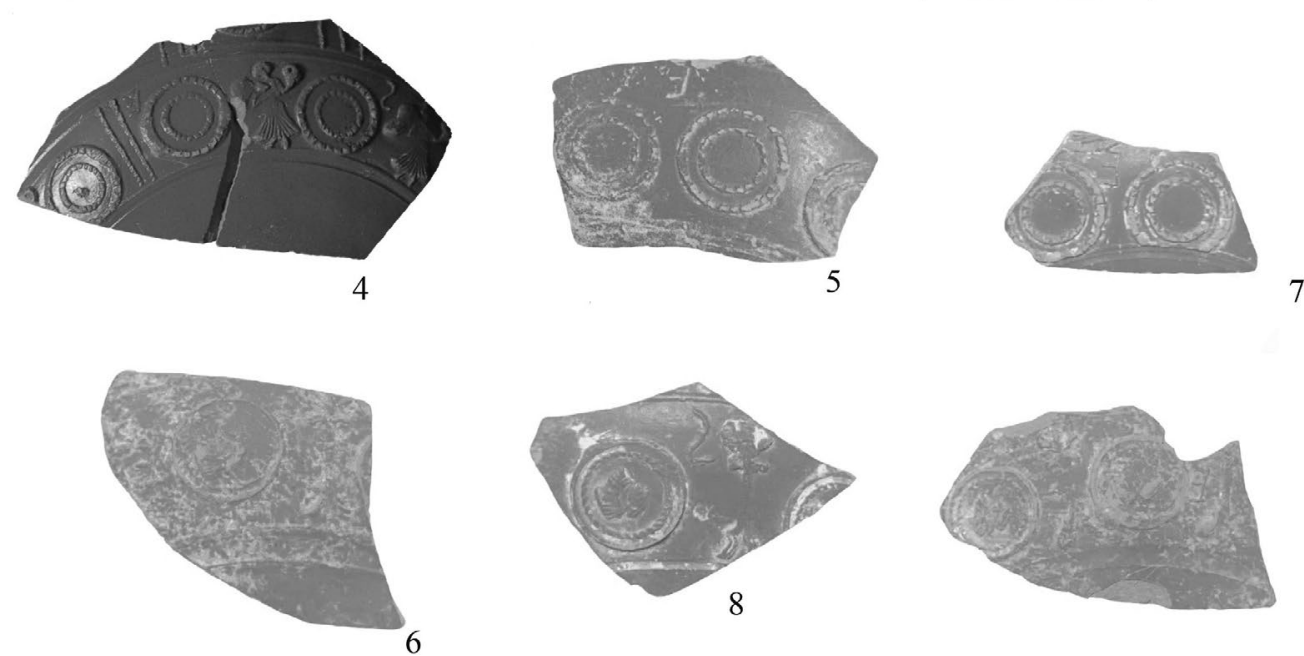

Figura 9: Fotografía de algunas de las piezas asociables a Sempronius
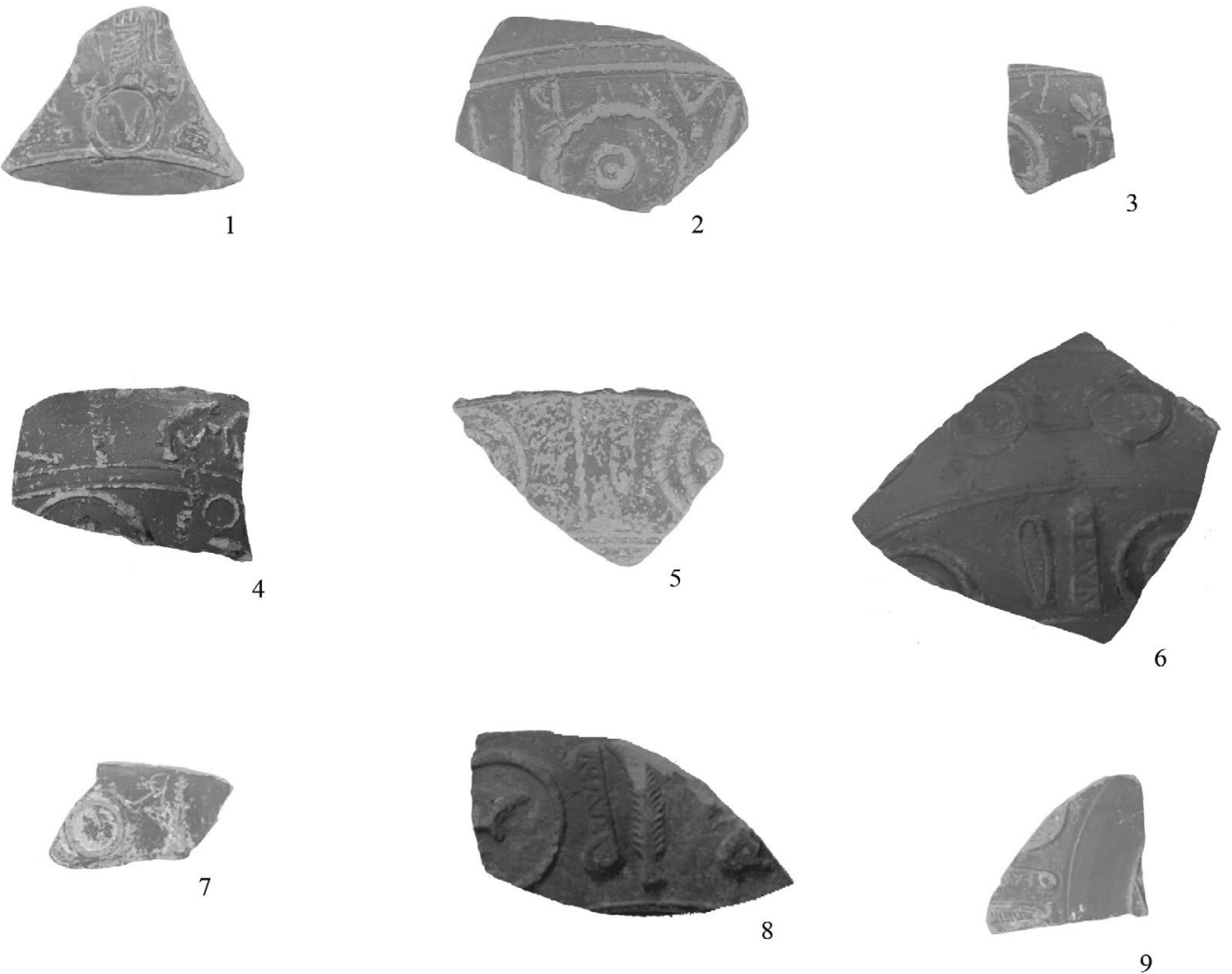

Figura 10: Fotografía de algunas de las piezas asociables a Valerius Paternus, parte I 

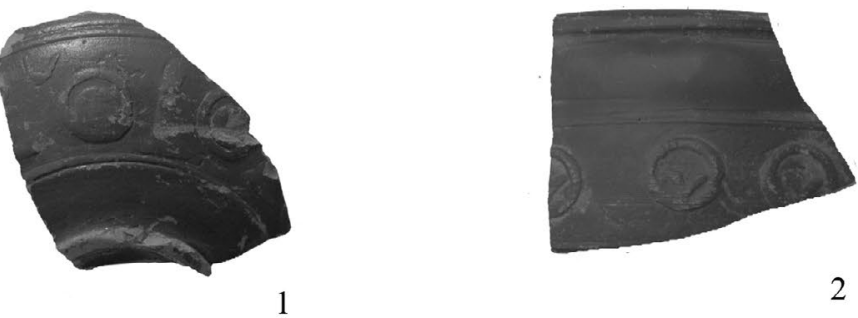

2

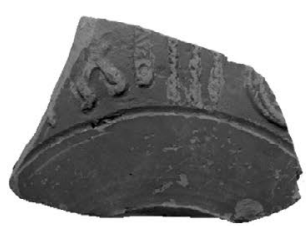

3

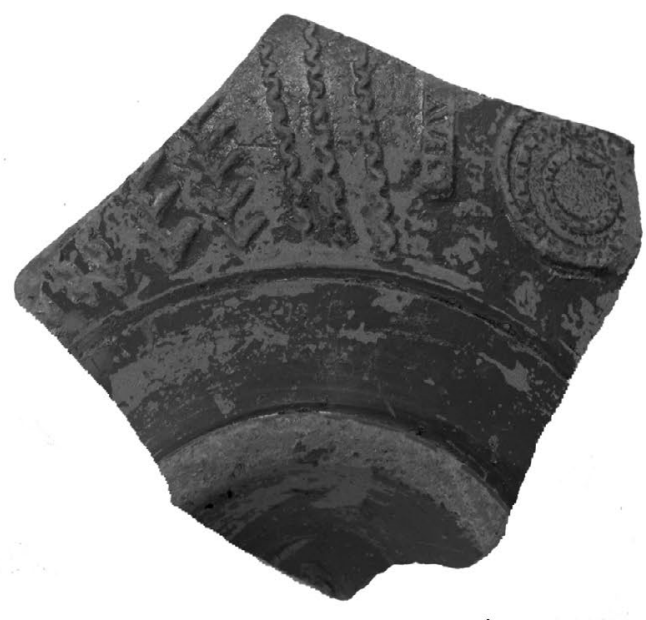

4

7

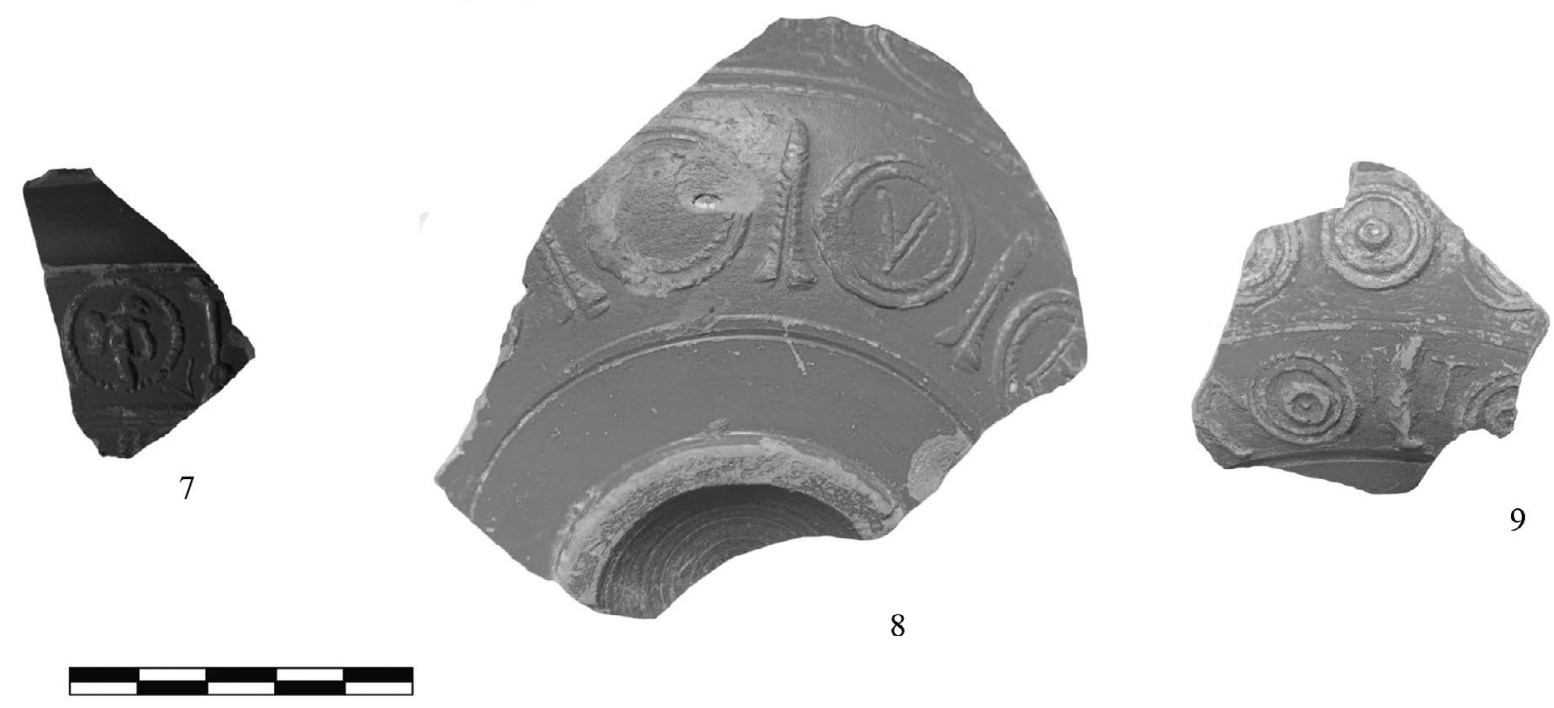

8
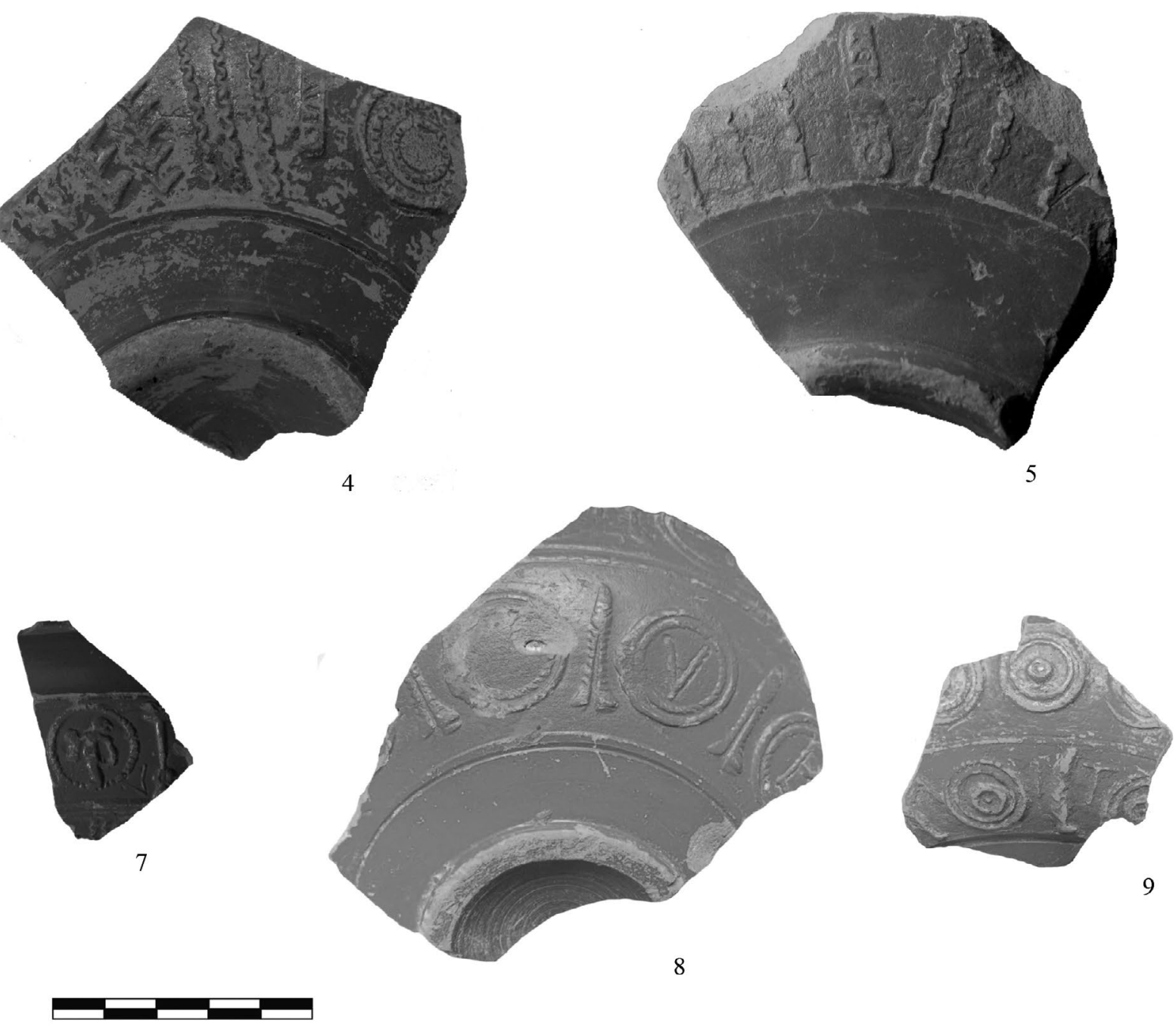

Figura 11: Fotografía de algunas de las piezas asociables a Valerius Paternus, parte II 

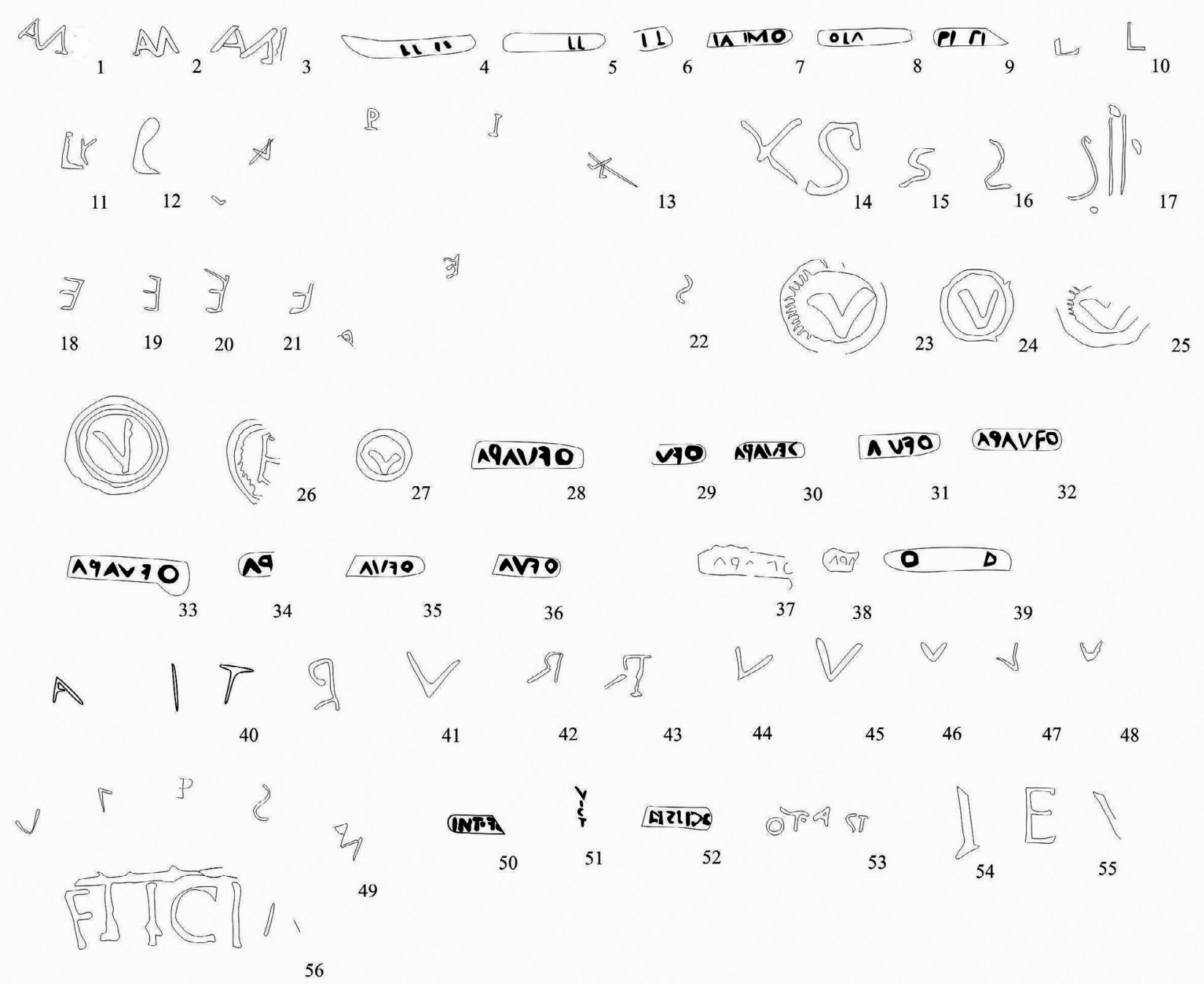

Figura 12: Sellos estudiado en el trabajo individualizados gráficamente

\begin{tabular}{|c|c|c|c|c|c|}
\hline IDENTIFICACIÓN & PROCEDENCIA & SIGLA & $\begin{array}{l}\text { TRANSCRIP- } \\
\text { CIÓN }\end{array}$ & $\begin{array}{l}\text { CRONOLOGÍA } \\
\text { DEL CONTEXTO }\end{array}$ & REFERENCIAS \\
\hline $\begin{array}{l}\text { Fig. 2:1; Fig. 7:1 y Fig. } \\
\text { 12:4 }\end{array}$ & $\begin{array}{l}\text { C/ Almendralejos, } \\
\text { 41, Mérida }\end{array}$ & $1535 / 182$ & (.)LLI(.) & $80-90$ d. C. & $\begin{array}{l}\text { Bustamante, 2013: lám. } \\
266,3\end{array}$ \\
\hline $\begin{array}{l}\text { Fig. 2:2; Fig. 7:3 y Fig. } \\
\text { 12:5 }\end{array}$ & $\begin{array}{l}\text { C/ Almendralejos, } \\
\text { 41, Mérida }\end{array}$ & $1535 / 2179$ & (.) $\operatorname{LL}()$. & $80-90$ d. C. & $\begin{array}{l}\text { Bustamante, 2013: lám. } \\
\text { 203, } 7\end{array}$ \\
\hline $\begin{array}{l}\text { Fig. 2:3; Fig. 7:4 y Fig. } \\
\text { 12:6 }\end{array}$ & $\begin{array}{l}\text { C/ Almendralejos, } \\
\text { 41, Mérida }\end{array}$ & $1285 / 623$ & {$[].(.) \mathrm{LI}$} & Mitad del II d. C. & $\begin{array}{l}\text { Bustamante, 2013: lám. } \\
266,5\end{array}$ \\
\hline $\begin{array}{l}\text { Fig. 2:4; Fig. 7:5; } \\
\text { Fig. 12:11 }\end{array}$ & Conimbriga & 111 & $\mathrm{~L}$ & Altoimperio & Inédito \\
\hline $\begin{array}{l}\text { Fig. 2:5; Fig. 7:7; Fig. } \\
\text { 12:7 }\end{array}$ & $\begin{array}{l}\text { C/ Almendralejos, } \\
\text { 41, Mérida }\end{array}$ & $1286 / 51$ & LA(.)ILIO & Mitad del II d. C. & $\begin{array}{l}\text { Bustamante, 2013: lám. } \\
225,5\end{array}$ \\
\hline $\begin{array}{l}\text { Fig. 2:6; Fig. 7:2; Fig. } \\
\text { 12:13 }\end{array}$ & $\begin{array}{l}\text { C/ Almendralejos, } \\
\text { 41, Mérida }\end{array}$ & $1319 / 23$ & LAPIA & Inicios del II d. C. & $\begin{array}{l}\text { Bustamante, 2013: lám. } \\
268,4\end{array}$ \\
\hline Fig. $2: 7$; Fig. $12: 10$ & El Saucedo & 80090 & [.]LL[.] & $\begin{array}{l}\text { Fines del III o } \\
\text { inicios del IV d. C. }\end{array}$ & Inédito \\
\hline $\begin{array}{l}\text { Fig. 2:8; Fig. 7:9; Fig. } \\
\text { 12:9 }\end{array}$ & $\begin{array}{l}\text { C/ Almendralejos, } \\
\text { 41, Mérida }\end{array}$ & $1378 / 11$ & (.)LI(.)LI & $\begin{array}{l}\text { Fines del II-inicios } \\
\text { del III d. C. }\end{array}$ & $\begin{array}{l}\text { Bustamante, 2013: lám. } \\
268,4\end{array}$ \\
\hline $\begin{array}{l}\text { Fig. 2:9; Fig. 7:6; Fig. } \\
\text { 12:12 }\end{array}$ & $\begin{array}{l}\text { C/ Almendralejos, } \\
\text { 41, Mérida }\end{array}$ & $1285 / 598$ & $\mathrm{~L}$ & Mitad del II d. C. & $\begin{array}{l}\text { Bustamante, 2013: lám. } \\
265,5\end{array}$ \\
\hline
\end{tabular}




\begin{tabular}{|c|c|c|c|c|c|}
\hline $\begin{array}{l}\text { Fig. } 2, \mathrm{n}^{\circ} .10 \text {; Fig. } 7: 8 \text {; } \\
\text { Fig. } 12: 8\end{array}$ & $\begin{array}{l}\text { C/ Almendralejos, } \\
\text { 41, Mérida }\end{array}$ & $1285 / 547$ & OLA(.) & Mitad del II d. C. & $\begin{array}{l}\text { Bustamante, 2013: lám. } \\
224,8\end{array}$ \\
\hline $\begin{array}{l}\text { Fig. 3:1; Fig. 8:1; Fig. } \\
12: 2\end{array}$ & MNAR, Mérida & 15326 & $M$ & Ignoto & Inédito \\
\hline $\begin{array}{l}\text { Fig. 3:2; Fig. 8:2; Fig. } \\
12: 1\end{array}$ & MNAR, Mérida & 14510 & A & Ignoto & Mayet, 1970: pl. 2, n. 5 \\
\hline Fig. 3:3; Fig. 12:3 & $\begin{array}{l}\text { Las Termas, } \\
\text { Talavera la Real }\end{array}$ & 119 & $\mathrm{~A}$ (retro) & Ignoto & Jerez Linde, 1996:119 \\
\hline $\begin{array}{l}\text { Fig. 4:1; Fig. 9:1; Fig. } \\
\text { 12:15 }\end{array}$ & MNAR, Mérida & 14474 & $\mathrm{~S}$ & Ignoto & Inédito \\
\hline $\begin{array}{l}\text { Fig. 4:2; Fig. 9:2; Fig. } \\
\text { 12:14 }\end{array}$ & MNAR, Mérida & 32263 & [.]XS[.] & Ignoto & Inédito \\
\hline $\begin{array}{l}\text { Fig. 4:3; Fig. 9:4; Fig. } \\
\text { 12:22 }\end{array}$ & $\begin{array}{l}\text { C/ Almendralejos, } \\
\text { 41, Mérida }\end{array}$ & $1286 / 46-83$ & ट马 M & Ignoto & $\begin{array}{l}\text { Bustamante, 2013: lám. } \\
225,4\end{array}$ \\
\hline $\begin{array}{l}\text { Fig. 4:4; Fig. 9:3; Fig. } \\
\text { 12:17 }\end{array}$ & Puticuli, Mérida & $8067 / 65 / 004$ & SII & Ignoto & Inédito \\
\hline $\begin{array}{l}\text { Fig. 4:5; Fig. 9:7; Fig. } \\
\text { 12:19 }\end{array}$ & MNAR, Mérida & 14680 & 본 & Ignoto & Inédito \\
\hline $\begin{array}{l}\text { Fig. 4:6; Fig. 9:8, Fig. } \\
12: 16\end{array}$ & MNAR, Mérida & 14402 & 2 & Ignoto & Inédito \\
\hline $\begin{array}{l}\text { Fig. 4:7; Fig. 9:5; Fig. } \\
\text { 12:21 }\end{array}$ & MNAR, Mérida & 14518 & 马ㅂ & Ignoto & Inédito \\
\hline $\begin{array}{l}\text { Fig. 4:8; Fig. 9:6; Fig. } \\
\text { 12:18 }\end{array}$ & MNAR, Mérida & 1784 & B & Ignoto & Inédito \\
\hline $\begin{array}{l}\text { Fig. 4:9; Fig. 9:9; Fig. } \\
\text { 12:20 }\end{array}$ & MNAR, Mérida & 14384 & 马 & Ignoto & Inédito \\
\hline $\begin{array}{l}\text { Fig. 5:1; Fig. 10:1; Fig. } \\
\text { 12:24 }\end{array}$ & MNAR, Mérida & 14646 & $\mathrm{~V}$ & Ignoto & Inédito \\
\hline Fig. 5:2; Fig. 12:23 & $\begin{array}{l}\text { La Orden, } \\
\text { Guadajira }\end{array}$ & 118 & $\mathrm{~V}$ & Ignoto & Jerez Linde, 1996:118 \\
\hline Fig. 5:3; Fig. 12: 25 & $\begin{array}{l}\text { Las Termas, } \\
\text { Talavera la Real }\end{array}$ & 117 & $\mathrm{~V}$ & Ignoto & Jerez Linde, 1996:117 \\
\hline Fig. 5:4; Fig. 12:44 & MNAR, Mérida & 14395 & $\mathrm{~V}$ & Ignoto & Inédito \\
\hline $\begin{array}{l}\text { Fig. 5:5; Fig. 10:2; Fig. } \\
12: 41\end{array}$ & Conimbriga & 110 & qV & Altoimperio & Inédito \\
\hline Fig. 5:6; Fig. 12:37 & $\begin{array}{l}\text { Cabezo II, } \\
\text { Hornachuelos }\end{array}$ & 115 & $\triangle ૧ \Lambda(.) \Gamma \mathrm{O}$ & Ignoto & Jerez Linde, 1996:115 \\
\hline Fig. 5:7; Fig. 12:38 & $\begin{array}{l}\text { Las Termas, } \\
\text { Talavera la Real }\end{array}$ & 116 & $\Lambda Ч \Lambda[]$. & Ignoto & Jerez Linde, 1996:116 \\
\hline $\begin{array}{l}\text { Fig. 5:8; Fig. 10:3; Fig. } \\
12: 43\end{array}$ & Conimbriga & 150 & [.]Я[.] & Ignoto & Inédito \\
\hline $\begin{array}{l}\text { Fig. 5:9; Fig. 10: 4; } \\
\text { Fig. 12:46 }\end{array}$ & $\begin{array}{l}\text { C/ Almendralejos, } \\
\text { 41, Mérida }\end{array}$ & $1319 / 382$ & $\mathrm{~V}$ & Inicios del II d. C. & $\begin{array}{l}\text { Bustamante, 2013: lám. } \\
225,14\end{array}$ \\
\hline $\begin{array}{l}\text { Fig. 5:10; Fig. 10:5; } \\
\text { Fig. 12:31 }\end{array}$ & MNAR, Mérida & 1787 & [.] АVम० & Ignoto & Inédito \\
\hline $\begin{array}{l}\text { Fig. 5:11; Fig. 10: 6; } \\
\text { Fig. 12:29 }\end{array}$ & $\begin{array}{l}\text { C/ Almendralejos, } \\
\text { 41, Mérida }\end{array}$ & $1319 / 360$ & १९ЯVनО & Inicios del II d. C. & $\begin{array}{l}\text { Bustamante, 2013: lám. } \\
2267,2\end{array}$ \\
\hline $\begin{array}{l}\text { Fig. 5:12; Fig. 10:7; } \\
\text { Fig. 12:42 }\end{array}$ & MNAR, Mérida & 1799 & Я & Ignoto & Inédito \\
\hline Fig. 5:13; Fig. 12:45 & MNAR, Mérida & Intra 6 & $\mathrm{~V}$ & Ignoto & Mayet, 1970: pl. 2, n. 6 \\
\hline Fig. 5:14; Fig. 12:32 & MNAR, Mérida & 14524 & १ЧИVमО & Ignoto & Mayet, 1970: pl. 1, n. 2 \\
\hline $\begin{array}{l}\text { Fig. 5:15; Fig. 10: } 8 \text {, } \\
\text { Fig. 12:33 }\end{array}$ & $\begin{array}{l}\text { C/ Almendralejos, } \\
\text { 41, Mérida }\end{array}$ & $1285 / 61$ & ЯЧИVमО & Mitad del II d. C. & $\begin{array}{l}\text { Bustamante, 2013: lám. } \\
265,2\end{array}$ \\
\hline $\begin{array}{l}\text { Fig. 5:16; Fig. 10: 9; } \\
\text { Fig. 12:29 }\end{array}$ & MNAR, Mérida & 19558 & [.]V'मО & Ignoto & Inédito \\
\hline Fig. 6:1; Fig. 12:30 & MNAR, Mérida & Intra 1 & АЧАV'НО & Ignoto & Mayet, 1970: pl. 1, n. 1 \\
\hline
\end{tabular}




\begin{tabular}{|c|c|c|c|c|c|}
\hline $\begin{array}{l}\text { Fig. } 6: 2 \text {; Fig. 11:1; Fig. } \\
\text { 12:48 }\end{array}$ & $\begin{array}{l}\text { C/ Almendralejos, } \\
\text { 41, Mérida }\end{array}$ & $1319 / 641$ & V & Inicios del II d. C. & $\begin{array}{l}\text { Bustamante, 2013: lám. } \\
260,4\end{array}$ \\
\hline $\begin{array}{l}\text { Fig. 6:3; Fig. 11:2; Fig. } \\
\text { 12:26 }\end{array}$ & $\begin{array}{l}\text { C/ Almendralejos } \\
\text { 41, Mérida }\end{array}$ & $1319 / 361$ & V & Inicios del II d. C. & $\begin{array}{l}\text { Bustamante, 2013: lám. } \\
257,9\end{array}$ \\
\hline $\begin{array}{l}\text { Fig. } 6: 4 \text {; Fig. 11:4; Fig. } \\
\text { 12:35 }\end{array}$ & $\begin{array}{l}\text { C/ Almendralejos, } \\
\text { 41, Mérida }\end{array}$ & $1285 / 958$ & [.] $\mathrm{AV}$ म० & Inicios del II d. C. & $\begin{array}{l}\text { Bustamante, 2013: lám. } \\
\text { 226, } 4\end{array}$ \\
\hline $\begin{array}{l}\text { Fig. 6:5; Fig. 11:5; Fig. } \\
\text { 12:39 }\end{array}$ & $\begin{array}{l}\text { C/ Almendralejos, } \\
\text { 41, Mérida }\end{array}$ & 14395 & $\mathrm{O}(,) \mathrm{D}$ & Mitad del II d. C. & Inédito \\
\hline $\begin{array}{l}\text { Fig. 6:6; Fig. 11:3; Fig. } \\
\text { 12:36 }\end{array}$ & $\begin{array}{l}\text { C/ Almendralejos, } \\
\text { 41, Mérida }\end{array}$ & $1285 / 571$ & [.] $\mathrm{AV}$ म० & Mitad del II d. C. & $\begin{array}{l}\text { Bustamante, 2013: lám. } \\
224,4\end{array}$ \\
\hline $\begin{array}{l}\text { Fig. } 6: 7 \text {; Fig. 11:8; Fig. } \\
\text { 12:26 }\end{array}$ & MNAR, Mérida & 1647 & V P & Ignoto & Mayet, 1970: pl. 2, n. 4 \\
\hline $\begin{array}{l}\text { Fig. } 6: 8 \text {; Fig. 11:9, Fig. } \\
12,40\end{array}$ & MNAR, Mérida & 1681 & [.]AIT[.] & Ignoto & Inédito \\
\hline Fig. 6:9; Fig. 32:34 & MNAR, Mérida & Intra 3 & $\Lambda$ १[.] & Ignoto & Mayet, 1970: pl. 1, n. 3 \\
\hline $\begin{array}{l}\text { Fig. 6:10; Fig. 11:7; } \\
\text { Fig. 32:47 }\end{array}$ & $\begin{array}{l}\text { C/ Almendralejos, } \\
\text { 41, Mérida }\end{array}$ & $1285 / 564$ & V & Mitad del II d. C. & $\begin{array}{l}\text { Bustamante, 2013: lám. } \\
225,6\end{array}$ \\
\hline Fig. 6:11; Fig. 12:49 & MNAR, Mérida & $\mathrm{S} / \mathrm{N}$ & VAPSam & Ignoto & Mezquíriz, 1960: lám. 7:5 \\
\hline $\begin{array}{l}\text { Fig. 3:4; Fig. 8:3; Fig. } \\
\text { 12:51 }\end{array}$ & Puticuli, Mérida & $8067 / 21 / 005$ & VICT & Fin del I d. C. & Inédito \\
\hline Fig. 3:5; Fig. 12:55 & El Saucedo & 80035 & [.]EV[.] & Siglo IV & Inédito \\
\hline Fig. 3:6; Fig. 12:54 & El Saucedo & 80315 & [.]II[.] & Siglo IV & Inédito \\
\hline $\begin{array}{l}\text { Fig. 3:7; Fig. 8:6; Fig. } \\
\text { 12:52 }\end{array}$ & $\begin{array}{l}\text { Ampliación } \\
\text { MNAR, Mérida }\end{array}$ & CE2014/9/223 & OCIISIF[.] & Fines del I d. C. & Inédito \\
\hline Fig. 3:8; Fig. 8:7 & $\begin{array}{l}\text { C/ Almendralejos, } \\
\text { 41, Mérida }\end{array}$ & $1285 / 620$ & Ilegible & Mitad del II d. C. & $\begin{array}{l}\text { Bustamante, 2013: lám. } \\
266,1\end{array}$ \\
\hline $\begin{array}{l}\text { Fig. 3:9; Fig. 8:5; Fig. } \\
\text { 12:56 }\end{array}$ & MNAR, Mérida & 27176 & [.]FICCI[.] & Ignoto & Inédito \\
\hline Fig. 3:10; Fig. 12:50 & Beja & 629 & IИT·'मО[.] & Ignoto & Mayet, 1984: pl. CCXIX \\
\hline Fig. 3:11; Fig. 12:53 & MNAR, Mérida & 8 & [.]OFAST[.] & Ignoto & $\begin{array}{l}\text { Mezquíriz, 1961: lám. 7:8 } \\
\text { y Mayet, 1984: pl. CCVIII }\end{array}$ \\
\hline
\end{tabular}

Figura 13: Cuadro sinóptico de las piezas analizadas

En relación a los alfareros localizados, concluimos cómo Valerius Paternus alcanza más del $46 \%$ de la muestra, le sigue Lapillus con un 17\%, Sempronius con un $16 \%$ y Victor con algo más de un $1 \%$. A esto hay que unirle otros ejemplares que entran dentro de la esfera de dudosos o ilegibles que alcanzan un algo más de un $10 \%$ de la muestra. Sin lugar a dudas, como anteriormente hemos puesto de relieve, se observa el predominio de los alfareros a los que anteriormente hemos aludido por tener a la región lusa como prioritaria para su comercialización (Valerius Paternus, Lapillus o Sempronius). Además, hay que tener en cuenta algunos problemas de lectura a los que hemos aludido. Estos surgen por la falta de un espacio adecuado que facilite el correcto desmolde del instrumental alfarero -desconfigurando la impresión- o bien la presión del punzón ejercida sobre el molde y no directamente sobre la pieza que podría obliterar los sellos o bien alterar los signos. A pesar de esto, únicamente, tenemos 2 ejemplares a los cuáles no podemos adscribirle ningún alfarero por falta de nitidez del epígrafe.
Del análisis de esta nómina de alfareros, unida a la que se conoce para el resto de Hispania, se puede concluir que el fenómeno, aunque no es tremendamente extenso, sí afecta a menos de un $8 \%$ de los productores norteños de sigillata ${ }^{13}$. Por lo tanto, lo que sí es reducido es el número de vasos que pudieron marcar, pero no el montante de alfareros insertos en este fenómeno.

En cuanto al soporte, de análisis tipológico se percibe un casi total monopolio de este fenómeno por parte de la forma Hisp. 37, aunque algunos quiebros angulosos podrían inducir a pensar de una pseudo variante Hisp. 29-37. A pesar de ello, la escasez de ejemplares completos nos fuerza a tomar esta última idea con cautela.

En relación a cuáles son los tipos de marcas que podemos definir son tres:

13. Para llevar a cabo esta estimación hemos tomado como referencia el número total de alfareros definidos por Sáenz y Sáenz (1999) y el elenco genérico presentado en este trabajo en el apartado 3. 
- inscripción en cartucho rectangular hecha a punzón (un 37\% de la muestra);

- como motivo decorativo formando parte de la composición ornamental bien como friso $(8,9 \%)$ o bien quedando las letras insertas en cartuchos circulares (algo más de un 7\% de la muestra).

- El restante $46 \%$ son letras hechas a mano alzada.

Independientemente del tipo, no se plasman directamente sobre la pieza, sino que se imprimen en el molde por lo que este último se articula como una interfaz que puede generar problemas de estampación.

En relación al tipo que usa cartuchos rectangulares ( $37 \%$ de la muestra), parece que no tienen un plan preconcebido y que una vez que todos los motivos están plasmados en el molde se intenta ajustar el motivo sin perturbar el esquema ya definido. El instrumental sería el mismo a usar en las piezas lisas, esto es los punzones de cartucho rectangular. Por lo tanto, presumiblemente, en este caso se plantea una función distinta ya que, si se persiguiera un mismo fin que cuando se usa en las piezas lisa, se pondría directamente en el fondo interior. Sin embargo, en este caso se muta a otro lugar con el hándicap añadido al que antes hicimos alusión que es más difícil de percibir por parte del usuario. En todos los ejemplares que asociamos a este tipo se observa un cierto respeto por el programa decorativo ya que se intenta no romper la composición. Los únicos ejemplos discordantes corresponderían a los de Lapillus (Fig. 2: 1-2) dentro de una composición corrida circular. En este caso, la cartela no pisa el motivo, pero sí genera cierta descompensación por su morfología al contrastar con los elementos circulares. A pesar de ello, sí hay un claro interés por ubicarlo paralelo al baquetón que separa el registro inferior del superior con el fin de compensar dicha ruptura. Claramente, se percibe cómo esta práctica está dirigida al alfarero en cuestión, así como a los que formaran parte del staff de la officina y no al usuario propiamente dicho. Una respuesta a esta incógnita podría ser que esta marca simplemente pretende dejar constancia de quién fue el artesano que elaboró el molde -el «mouliste»- que no tendría que ser el mismo que modelara y concluyera la pieza -el «potier»- (Mees, 1994). Esta idea apoyaría el posible trasiego de moldes no sólo dentro de un mismo alfar sino, de igual modo, fuera de las unidades productivas que hicieran necesario el marcado del instrumental para evitar pérdidas. Sin embargo, para dejar constancia de la autoría de un molde existen diversos mecanismos que no fuerzan a que la pieza lleve una marcación pre cocturam. De hecho, existen otro tipo de marcas atestiguadas sobre los moldes que no quedarían expresamente marcadas en las piezas conclusas -al estar en el exterior o parte inferior de estos instrumentos-que nos dan buena prueba de que el interés del maestro alfarero por mostrar su autoría sería ínfimo.

En relación al segundo tipo de marca, como motivos decorativos formando parte del discurso ornamental tenemos dos apartados, por un lado, letras dentro de cartuchos circulares $(7 \%)$ y por otro las letras corridas dentro ocupando todo el friso $(8,9 \%)$. Dentro de las letras en cartucho circular, tenemos una $\mathrm{V}$ que, en algún caso, está acompañada por una $\mathrm{P}$ así como una $\mathrm{S}$. En lo referido a la $\mathrm{V}$ claramente puede tener dos lecturas. La primera de ellas referida a una posible bifoliacea y la segunda una V mayúscula. De ambas descartamos la primera ya que entendemos que el motivo final sería demasiado simplista atendiendo a los otros discursos compositivos localizados. El otro gran conjunto son las piezas que cuentan una inscripción que se ocuparía todo el friso superior ${ }^{14}$. Aunque son conocidas las fórmulas propiciatorias en las cerámicas no podemos calificar si estos ejemplos serían vinculables o no a este tipo de prácticas debido a su estado fragmentario. Independientemente de que se encuentre en cartela circular o que aparezca en todo el friso, este tipo presenta como singularidad que, únicamente, se puede usar en ejemplares decorados y no en lisos como sí ocurre en el anterior ejemplo -cartuchos rectangulares-. De igual modo, aquí se observa cómo claramente hay una intención a que el usuario perciba lo que allí se ha plasmado. De hecho, a diferencia de lo que suele ocurrir con las inscripciones en ámbito decorativo que son retrógradas aquí aparecen desarrolladas de izquierda a derecha. Este interés en que se perciban se acentúa por el hecho de que aparecen en los frisos superiores y no en los inferiores que entran en un segundo plano del campo visual.

En relación al tercer tipo, a mano alzada hecha en molde aún fresco, tenemos un $46 \%$ de la muestra. En este caso, se observa cómo el grosor de las líneas de las letras varía lo que nos permite definir que no existe un plan preconcebido. Las letras terminan incluyéndose entre la decoración sin afectar a la composición final y, en algunas ocasiones, se imprimieron en el molde teniendo presentes al consumidor final ya que la lectura se puede formular de izquierda a derecha y no retrógrada. En este grupo hay que destacar un caso significativo de Lapillus (Fig. 2: 6) cuya lectura únicamente se puede completar si se produce el giro total del vaso. Uno de los elementos que más se reitera es que los trazos de las letras son finos y poco abultados que inicialmente podría haber apuntado a una posible marca interna del alfar. Sin embargo, el que aparezcan algunos ejemplares de izquierda a derecha habla de intención de captar la atención del consumidor final.

Como ya hemos indicado, de los tres tipos, el que hace uso de sellos en cartuchos rectangulares, claramente, funciona de espaldas al consumidor final de la pieza ya que no se observa ningún tipo de guiño que facilitara a éste la lectura. En los otros casos sí se observa cómo se quiere compartir claramente con el

14. Volvemos a aludir de nuevo a las marcas [.]Bo[.] y [.]Anno $\operatorname{In}[$.$] que hemos comentado en el punto 3.1. cuya ubicación$ y tamaño no concuerda con los otros sellos y que podrían abrir otros ejemplos de diálogos de los productores con el consumidor. 
usuario el contenido ya que, al menos, se hacen inteligibles dichos signos. Sin embargo, el escaso impacto que tuvo en el registro hispano claramente es indicativo del posible fracaso de esta práctica si, en algún momento, tuvo interés de entrar en contacto con el público. Es evidente que las estrategias de marketing visual en la antigüedad tuvieron una gran importancia a la hora de plantear estas empresas de amplio espectro como pudo ser la producción de sigillata.

Aunque no queremos plantear reflexiones que caigan en posibles paralelos anacrónicos es evidente que, lo mismo que ocurre en la actualidad, se pudo fijar determinados signos distintivos que, con una simple autopsia visual, se asociaran a talleres o a artesanos. Estos elementos, paragonables con nuestros «logos», supondrían un posible signo de calidad que, claramente, fuera reclamado por causas que no podemos determinar en la actualidad. Sin embargo, las prácticas de emulación -con sobremodelaje o no- de los motivos por parte de otros alfareros, no sólo en el seno del mismo alfar terminaría siendo algo común por lo que la idea de exclusividad en este sentido sería bastante transitoria. Otros autores, por el contrario, niegan la posible premeditación por parte de los alfareros por incluir determinados motivos y por definir una determinada imagen estética. Hablan, más bien, de una respuesta rápida hacia una demanda abrumadora de moldes (Mees, 1994: 19) pero que, creemos firmemente, llevarían implícitos la reiteración de determinados motivos o composiciones cercanos ya algunos alfareros.

Del estudio individualizado de los motivos -epigráficos o no- que terminan reiterándose, se podría concluir que hubo determinados elementos que fueron muy recurrentes en la producción de officinae concretas y que, incluso, pudieron terminar siendo marcas identitarias de su producción, inclusive, dentro de una misma figlina. Esto, evidentemente, radica en la presencia de unas herramientas propias que no se transfieren y que intentan expresar la voluntad del artesano por marcar unos productos, algunos de ellos -los lisos- tremendamente estandarizados, con algunas marcas que quedan fuera de la inteligibilidad del público general y que, posiblemente, exteriorizan la organización interna de su trabajo fuera de los límites del alfar la relación entre el officinator y el dominus de los medios de producción (De Donno, 2005: 170-175). Sin embargo, esta idea se diluye en el momento en el que los signos se mimetizan externamente con la producción decorada y ese simple «oteo» de cuantificación precisara de una autopsia más concreta que incluso llevara pareja el levantado de la pieza o su girado.

Sin lugar a dudas, el fenómeno del marcado en la sigillata, como ya avanzamos con la inicial cita de Pucci, sigue siendo una gran incógnita que, incluso se complica más en el momento que dichas marcas se insertan en abigarradas decoraciones y cuya impresión es parcial. Creemos que esta última idea es la que, claramente, nos muestra que los productores de moldes en ningún momento tuvieron en cuenta al consumidor en la plasmación de estos sellos pudiendo ser una mera actitud caprichosa asociada al artist's mood at the moment (Beazley, 1944: 33).

\section{REFERENCIAS}

Abásolo, J. A. (1976-1977). El yacimiento arqueológico de Castrojeriz. Avance al estudio de las cerámicas indígenas. Sautuola, II, 263-280.

Acuña, P. y Elorza, J. C. (1974). Notas sobre cerámica romana en la provincia de Álava. Estudio de Arqueología Alavesa, 6, 169-171.

Almagro, M. y Caballero, L. (1968-1972). Tres vasos excepcionales de cerámica sigillata. El alfar de Miccio. Revista de Archivos, Bibliotecas y Museos, LXXV(1-2), 511-566.

Beazley, J. D. (1944). Potter and painter in Ancient Athens. London: G. Cumberledge.

Bémont, C., Vernhet, A. y Beck, F. (1987). La Graufesenque, village de potiers gallo-romains. Catalogo della Mostra. Paris: Ministère de la Culture et de la Communication.

Boube, S. (1965). Terra sigillata hispanique en Maurétanie Tingitane, I: Marques de potiers. Rabat: ETAM.

Boube, S. (1966). La terra sigillata hispanique en Maurétanie Tingitane: Supplément au catalogue des marques de potiers. Bulletin d'Archéologie Marocaine, VI, 115-142.

Boube, S. (1968-1972a). La terra sigillata hispanique en Maurétanie Tingitane, supplément. II au catalogue des potiers. Bulletin d'Archéologie Marocaine, VIII, 67-126.

Boube, S. (1968-1972b). Les fouilles de la nécropole de Sala et la chronologie de la terra sigillata hispanique. Bulletin d'Archéologie Marocaine, VIII, 109-118.

Bustamante-Álvarez, M. (2013). La terra sigillata en Augusta Emerita. Estudio tipocronológico a partir de los vertederos del suburbio norte. Anejos de Archivo Español de Arqueología, LXV. Mérida: CSIC.

Buxeda, J. y Madrid, M. (2013). Estudio de caracterización arqueométrica de cerámicas finas altoimperiales procedentes de la ciudad romana de Augusta Emerita. En M. BustamanteÁlvarez. La terra sigillata en Augusta Emerita. Estudio tipocronológico a partir de los vertederos del suburbio norte (anexo VI). Anejos de Archivo Español de Arqueología, LXV. Mérida: CSIC.

Carandini, A. (1979). L'anatomia della scimmia. La formazione económica della società prima del Capitale. Torino: G. Einaudi.

Carreño Gascón, M. C. (1997). Marcas de alfarero sobre terra sigillata halladas en Lucus Augusti. A Coruña: Ed. Do Castro.

Castro García, L. de. (1975). Unos interesantes grafitos de Calzadilla de la Cueza (Palencia). Boletín de la Asociación Española de Amigos de la Arqueología, 3, 24-27.

Comfort, H. (1961). Roman ceramics in Spain: an exploratory visit. Archivo Español de Arqueología, XXXIV, 3-17. 
Dannell, G. (2002). Law and Pratice: Further thoughts on the organization of the potteries at la Graufesenque, En Céramiques de La Graufesenque et autres produtions d'époque romaine - Nouvelles Recherches - Hommages à Bettina Hoffman (pp. 211-242). Col. Archéologie et Histoire Romaine, 7. Millau: Éditions Monique Mergoil.

De Donno, M. (2005). I marchi di fabbrica e la terra sigillata. En D. Gandolfi (Ed.). La ceramica e i materiali di età romana. Classi, produzioni, commerci e consumi (pp. 169182). Roma: Istituto Internazionale di Studi Liguri.

Dickinson, B. et al. (2008-2016). Names on Terra Sigillata. An Index of Makers'Stamps \& Signatures on Gallo-Roman Terra Sigillata (Samian Ware). London: University of London Institute of Classical Studies.

Ettingler, E. y Fellmann, R. (1955). Ein sigillata depotfund aus den Legionslager Vindonissa. Germania, 33, 364-373.

Fernández-Galiano Ruíz, D. (1976). Una interesante tumba romana en Complutum (Alcalá de Henares). Noticiario Arqueológico Hispánico, 4, 585-605

Garabito Gómez, T. (1978). Los Alfares Romanos Riojanos. Producción y Comercialización. Col. Bibliotheca Praehistorica Hispana, 16. Madrid: Consejo Superior de Investigaciones Científicas.

García Marcos, V. (1990). Marcas de alfarero en sigillata hispánica halladas en la ciudad de León. Tierras de León: Revista de la Diputación Provincial, 30, 89-114.

Genin, M. (2007). La Graufesenque (Millau, Aveyron). Sigillées lisses et autres productions. Pessac: Éditions de la Fédération Aquitania.

Hartley, B. R. (1977). Some wandering potters. En J. Dore y K. Greene (Eds.). Roman pottery studies in Britain and beyond (pp. 251-261). BAR, Supplementary Series, 30. Oxford: British Archaeological Reports.

Hoyo, J. del, López Pérez, A. M. ${ }^{\text {a }, ~ C a s t e l o ~ R u a n o, ~ R ., ~ B u s t a-~}$ mante-Álvarez, M., Blanco García, J. F. y Zamora Merchán, M. (2021). Hábitos epigráficos sobre cerámica en la villa romana de El Saucedo (Talavera la Nueva, Toledo). Los grafitos. Boletín del Museo Arqueológico Nacional, 40, 67-94.

Jerez Linde, J. M. (1996). Valerivs Paternvs: Notas para la clasificación tipológica de las marcas alfareras procedentes de la cuenca media del Guadiana. Mélanges de la Casa de Velázquez, Antiquité-Moyen-Âge, 32(1), 113-138. DOI: https://doi.org/10.3406/casa.1996.2761

Juan Tovar, L. C. (1988). Nuevos datos sobre el alfar de sigillata de Talavera de la Reina (Toledo). En Actas del I Congreso de Historia de Castilla-La Mancha, vol. IV (pp. 141-144). [Toledo]: Servicio de Publicaciones de la Junta de Comunidades de Castilla-La Mancha.

Juan Tovar, L. C. (1992). Terra Sigillata Hispánica. En L. Caballero (Ed.). Arcóbriga II - Las Cerámicas Romanas (pp. 35-134). Zaragoza: Institución Fernando El Católico.

Martín Bueno, M. (1976). Aportaciones al conocimiento de la terra sigillata de Bilbilis. Principe de Viana, 142-143, 67-118.
Mayet, F. (1970). À propos de deux potiers de Mérida: Valerius Paternus et Lapillus. Mélanges de la Casa de Velázquez, 6, 5-41. DOI: https://doi.org/10.3406/casa.1970.1012

Mayet, F. (1984). Les céramiques sigillées hispaniques: contribution à l'histoire économique de la Péninsule Ibérique sous l'Empire Romain. Paris: Centre Pierre Paris. De Boccard.

Mees, A. (1994). Potiers et moulistes. Observations sur la chronologie, les strutures et la commercialization des ateliers de terre sigillée décorée. En Actes du Coloque de Millau (Millau 1994) (pp. 19-42). Millau: Sociéte Française pour l'Étude de la Céramique Antique en Gaule.

Mezquíriz de Catalán, M. A. (1961). Terra Sigillata Hispánica. Valencia: The William L. Bryant Foundation.

Mezquíriz de Catalán, M. A. (1985). Terra Sigillata Hispanica. En VV. AA. (Eds.). Enciclopedia dell'Arte Antica Classica e Orientale, II, Ceramica fine romana nel bacino Mediterraneo (Tardo Ellenismo e Primo Imperio) (pp. 97-174). Roma: Istituto della Enciclopedia Italiana.

Montesinos i Martínez, J. (1991). Terra sigillata en Ilici: productos hispánicos. Saetabi, 41, 133-156.

Morel, J.-P. (1976). Aspects de l'artisanat dans la Grande Grèce romaine. En VV. AA. (Eds.). La Magna Grecia in etapa romana, Atti del XV convegno di Studi della Magna Grecia (pp. 263-324). Taranto: Istituto per la Storia e l'Archeologia della Magna Grecia.

Morel, J.-P. (1988). Artisanat et colonisation dans l'Italie romaine aux IV et III siècles av. J.C. Dialoghi di Archeologia, 6, 49-63.

Nieto Gallo, G. (1958). El oppidum de Iruña (Álava). Vitoria: Diputación Foral de Álava.

Oswald, F. (1931). Index of potters' Stamps on terra sigillata «Samian Ware». East Bridgford: Margidunum

Oxé, A. y Comfort, H. (1968). Corpus Vasorum Arretinorum. A catalogue of the signatures, shapes and chronology of Italian Sigillata. Bonn: Habelt.

Oxé, A., Comfort, H. y Kenrick, P. (2000). Corpus Vasorum Arretinorum. A catalogue of the signatures, shapes and chronology of Italian Sigillata. Bonn: Habelt.

Oyen, A. van. (2015). The roman city as articulated through terra sigillata. Oxford Journal of Archaeology, 34(3), 279-299. DOI: https://doi.org/10.1111/ojoa.12059

Paz Peralta, J. A. (2008). Las producciones de terra sigillata hispánica intermedia y tardía. En D. Bernal y A. Ribera (Ed.). Cerámicas Hispanorromanas: un estado de la cuestión (pp. 497-540). Cádiz: Universidad de Cádiz.

Pedroni, L. (1995). Riflessioni sulla nascita dell'aretina. Ostraka, IV(1), 169-191

Pérez Almoguera, A. (1990). La «terra sigillata» de l'antic Portal de Magdalena. Lleida: Ajuntament de Lleida.

Polak, M. (2000). South Gaulish Terra Sigillata with Potters' Stamps from Vechten, Nijmegen. Col. Rei Cretariae Romanum Fautorum Acta, Supplementum, 9. Nijmegen: Rei Cretariae Romanae Fautores 
Pucci, G. (1993). I bolli sulla terra sigillata: fra epigrafia e storia economica. En W. V. Harris (Ed.). The inscribed economy. Prodution and distribution in the Roman empire in the light of instrumentum domesticum (pp. 73-79). Journal of Roman Archaeology Supplementary Series, 6. Michigan: Ann Harbor.

Roca Roumens, M. y Fernández García, M. I. (Eds.). (1999). Terra Sigillata Hispánica. Centros de fabricación y producciones alto-imperiales. Málaga: Universidad de Málaga.

Romero Carnicero, M. V. (1978). Vllo, un alfarero de terra sigillata hispánica. Boletín del Seminario de Arte y Arqueología, XLIV , 105-128.

Romero Carnicero, M. V. (1984). Sobre ciertas producciones precoces de sigillata en la Península Ibérica: los ceramistas Asiaticus y Maternus y nuevos vasos de M.C.R. Boletín del Seminario de Arte y Arqueología, L, 91- 112.

Romero Carnicero, M. V. (1985). Numancia, I. La terra sigillata. Excavaciones Arqueológicas en España, 146. Madrid: Ministerio de Cultura y Deporte.

Romero Carnicero, M. V. (1986). Los vasos de terra sigillata firmados por TITI SAGENI. Numantia, II, 237-244.

Romero Carnicero, M. V. (2020). A propósito del nombre de un alfarero: ¿VLLO o mejor ATTO? Anejos de Cuadernos de Prehistoria y Arqueología de la Universidad Autónoma de Madrid, 4, 349-361. DOI: https://doi.org/10.15366/ane4. ochoa2020.028

Romero Carnicero, M. V., Crespo Mancho, M. J. y Lión Bustillo, C. (2016). De nuevo sobre «M.C.R.», «Asiaticus» y «Maternus». Boletín del Seminario de Arte y Arqueología, $82,155-193$.

Russel Cortez, F. (1951). Da terra sigillata tardía encontrada en Portugal. Viseu: Centro de Estudos de Etnologia Peninsular.

Saénz Preciado, J. C. (1997). La terra sigillata hispánica del Municipium Augusta Bilbilis. (Tesis doctoral). Universidad de Zaragoza. Zaragoza. Recuperado de: https://zaguan. unizar.es/record/4574? In=es

Saénz Preciado, J. C. (2018). La terra sigilata hispánica en los contextos cerámicos del municipium Augusta Bilbilis. Zaragoza: Diputación de Zaragoza, Institución Fernando el Católico.
Sáenz Preciado, M. P. (1994). Marcas y grafitos del centro alfarero de La Cereceda (Arenzana de Arriba, La Rioja). Berceo, 127, 79-113.

Sáenz Preciado, M. P. (1997). El centro alfarero de la Cereceda (Arenzana de Arriba, La Rioja). Las producciones del alfarero de las hojas de trébol y del alfarero de los bastoncillos segmentados. Salduie, 6, 195-211.

Sáenz Preciado, M. P. y Sáenz Preciado, J. C. (1999). Estado de la cuestión de los alfares Riojanos: la Terra Sigillata Hispánica Altoimperial. En M. Roca Roumens y M. I. Fernández García (Eds.). Terra Sigillata Hispánica: Centros de fabricación y producciones altoimperiales, Homenaje a $M$. ángeles Mezquíriz (pp. 61-136). Málaga: Universidad de Málaga.

Sáenz Preciado, M. P. y Sáenz Preciado, J. C. (2015). Forma IXX IMPERATORII CAIISARII DOMITIANO. En M. I. Fernández García, P. Ruiz Montes y M. V. Peinado Espinosa (Eds.). Terra sigillata hispánica. 50 años de investigación (pp. 179-188). Roma: Quasar.

Sánchez-Lafuente Pérez, J. (1985). Comercio de cerámicas romanas en Valeria. Serie Arqueológica Conquense. Cuenca: Diputación Provincial de Cuenca.

Sánchez-Lafuente Pérez, J. (1990). Terra sigillata de Segobriga y ciudades del entorno: Valeria, Complutum y Ercavica. (Tesis doctoral inédita). Universidad Complutense. Madrid.

Schnurbein, S. von. (1982). Die unverzierte Terra Sigillata aus Haltern, Bodenaltertümer Westfalens. Münster: Aschendorff.

Siebert, G. (1978). Signatures d'artistes, d'artisans et de frabricants dans l'Antiquité classique. Ktema, 3, 111-135. DOI: https://doi.org/10.3406/ktema.1978.1793

Simón Cornago, I. (2016). Los alfareros de terra sigillata hispánica con nombre indígena. Paleohispánica. Revista sobre lenguas y culturas de la Hispania Antigua, 16, 95-113.

Simón Cornago, I. (2017). Los alfareros de Tritium Magallum. Revue des Etudes Anciennes, 119(2), 485-520.

Simón Cornago, I. (2020). Valerius Maternus, productor de vasos lisos y decorados de terra sigillata hispánica. Epigraphica, LXXXII(1-2), 460-461.

Sotomayor, M. (1977). Marcas y estilos en la sigillata decorada en Andújar (Jaén). Jaén: Instituto de Estudios Gienenses. 
